\title{
Molecular Mechanisms, Biomarkers and Emerging Therapies for Chemotherapy Resistant TNBC
}

\author{
Paola Ferrari ${ }^{1, *}$, Cristian Scatena ${ }^{2}\left(\mathbb{D}\right.$, Matteo Ghilli ${ }^{3} \mathbb{D}$, Irene Bargagna ${ }^{4}$, Giulia Lorenzini ${ }^{4}$ and $^{4}$ \\ Andrea Nicolini ${ }^{4,+}$
}

check for updates

Citation: Ferrari, P.; Scatena, C.; Ghilli, M.; Bargagna, I.; Lorenzini, G.; Nicolini, A. Molecular Mechanisms, Biomarkers and Emerging Therapies for Chemotherapy Resistant TNBC. Int. J. Mol. Sci. 2022, 23, 1665. https://doi.org/10.3390/ijms23031665

Academic Editor: Chiara Laezza

Received: 17 December 2021

Accepted: 25 January 2022

Published: 31 January 2022

Publisher's Note: MDPI stays neutral with regard to jurisdictional claims in published maps and institutional affiliations.

Copyright: (C) 2022 by the authors. Licensee MDPI, Basel, Switzerland. This article is an open access article distributed under the terms and conditions of the Creative Commons Attribution (CC BY) license (https:// creativecommons.org/licenses/by/ $4.0 /)$.
1 Unit of Oncology 1, Department of Medical and Oncological Area, Pisa University Hospital, 56126 Pisa, Italy 2 Division of Pathology, Department of Translational Research and New Technologies in Medicine and Surgery, University of Pisa, 56126 Pisa, Italy; cristian.scatena@unipi.it

3 Unit of Breast Surgery, Breast Cancer Center, University Hospital of Pisa, 56126 Pisa, Italy; m.ghilli@ao-pisa.toscana.it

4 Unit of Medical Oncology, Department of Translational Research and New Technologies in Medicine, University of Pisa, 56126 Pisa, Italy; irene.bargagna@hotmail.it (I.B.); lorenzinigiuli@gmail.com (G.L.); andrea.nicolini@med.unipi.it (A.N.)

* Correspondence: p.ferrari@ao-pisa.toscana.it

+ Retired.

\begin{abstract}
Triple-negative breast cancer (TNBC) is associated with high recurrence rates, high incidence of distant metastases, and poor overall survival (OS). Taxane and anthracycline-containing chemotherapy (CT) is currently the main systemic treatment option for TNBC, while platinum-based chemotherapy showed promising results in the neoadjuvant and metastatic settings. An early arising of intrinsic or acquired CT resistance is common and represents the main hurdle for successful TNBC treatment. Numerous mechanisms were uncovered that can lead to the development of chemoresistance. These include cancer stem cells (CSCs) induction after neoadjuvant chemotherapy (NACT), ATP-binding cassette (ABC) transporters, hypoxia and avoidance of apoptosis, single factors such as tyrosine kinase receptors (EGFR, IGFR1), a disintegrin and metalloproteinase 10 (ADAM10), and a few pathological molecular pathways. Some biomarkers capable of predicting resistance to specific chemotherapeutic agents were identified and are expected to be validated in future studies for a more accurate selection of drugs to be employed and for a more tailored approach, both in neoadjuvant and advanced settings. Recently, based on specific biomarkers, some therapies were tailored to TNBC subsets and became available in clinical practice: olaparib and talazoparib for BRCA1/2 germline mutation carriers larotrectinib and entrectinib for neurotrophic tropomyosin receptor kinase (NTRK) gene fusion carriers, and anti-trophoblast cell surface antigen 2 (Trop2) antibody drug conjugate therapy for heavily pretreated metastatic TNBC (mTNBC). Further therapies targeting some pathologic molecular pathways, apoptosis, miRNAS, epidermal growth factor receptor (EGFR), insulin growth factor 1 receptor (IGF-1R), and androgen receptor (AR) are under investigation. Among them, phosphatidylinositol 3 kinase (PI3K)/protein kinase B (Akt)/mammalian target of rapamycin (mTOR) and EGFR inhibitors as well as antiandrogens showed promising results and are under evaluation in Phase II/III clinical trials. Emerging therapies allow to select specific antiblastics that alone or by integrating the conventional therapeutic approach may overcome/hinder chemoresistance.
\end{abstract}

Keywords: breast cancer; triple-negative; chemoresistance; biomarkers; emerging therapies

\section{Introduction}

Triple-negative breast cancer (TNBC) is defined as a tumor lacking estrogen (ER) and progesterone (PR) receptor expression and human epidermal growth factor receptor 2 (HER2) overexpression/amplification. TNBC represents $10-20 \%$ of breast cancers and is more frequent in young women [1]. As compared to that of the other breast cancer (BC) subtypes, TNBC is associated with higher incidence of recurrence and distant metastases, and shorter 
overall survival (OS) [2]. Despite better pathological complete response (pCR) rates after neoadjuvant chemotherapy, prognosis of TNBC patients is worse as compared to non-TNBC tumors; this phenomenon is known as "triple negative paradox" [3]. In TNBC patients, disease progression and recurrence typically occur within the first $3-5$ years after diagnosis; brain and lung metastases are more common [2,4]. This behavior is attributed to higher biological aggressiveness, including the emergence of resistance to chemotherapy (CT), which is the mainstay treatment in TNBC. In fact, although chemoresistance is shared with most other malignancies, an intrinsic origin or an earlier occurrence is much more common in this molecular subtype. TNBC is usually diagnosed by immune-histochemistry (IHC).

Basing upon gene expression patterns, five molecular subtypes of breast cancer with distinctive clinical behavior were identified, i.e., Luminal A, Luminal B, Her-2 enriched, Normal-like, and Basal-like [5,6]. Among them, basal-like breast cancers are most commonly triple-negative. However, these two terms are not synonymous, as $70-80 \%$ of TNBCs are basal-like and about $70 \%$ of basal-like cancers are triple-negative [6]. More recently, a TNBC subgroup termed claudin-low molecular subtype was identified. This subtype lacks basal markers and is enriched in stem cell and epithelial-mesenchymal transition (EMT) markers [7]. Overall, these findings underline the heterogeneous nature of TNBC.

In early-stage $\mathrm{TNBC}$, various rates of $\mathrm{pCR}$ after neoadjuvant chemotherapy (NACT) as well as different response to treatment and different survival in the metastatic setting were found [8]. Tumor heterogeneity and multiple mechanisms of chemoresistance may be largely responsible for this phenomenon $[9,10]$. The molecular heterogeneity of TNBC was better clarified by genomic sequencing studies. In particular, basal-like 1 (BL1), basallike 2 (BL2), immunomodulatory (IM), mesenchymal (M), mesenchymal stem-like (MSL), and luminal androgen receptor (LAR) molecular subtypes were identified [9]. A further classification into four subtypes was made by Burstein et al.: androgen receptor (AR) positive, mesenchymal, basal-like immune sup-pressed, and basal-like immune activated [10]. These subtypes might predict response to targeted therapy; however, they are not used in clinical practice, and cytotoxic chemotherapy remains the mainstay in TNBC treatment. This review, after having briefly examined the chemotherapeutic regimens recommended by current guidelines in the different settings, focuses on the main mechanisms reported to be responsible of chemoresistance in TNBC. Successively, biomarkers helpful in predicting resistance to chemotherapy and drugs either currently recommended or potentially useful in chemoresistant TNBC are considered.

\section{Chemotherapy}

CT is currently the principal therapeutic option in TNBC. Preferred regimens include taxanes and anthracyclines; platinum-based regimens are also used in neo-adjuvant and metastatic settings [11].

\subsection{Neo-Adjuvant Setting}

Current guidelines recommend as preferred regimens: doxorubicin (or epirubicin)cyclophosphamide combination (dose dense or every 3 weeks) followed by paclitaxel with or without carboplatin; docetaxel-cyclophosphamide combination; olaparib if germline $B R C A 1 / 2$ mutation; addition of pembrolizumab in high-risk patients [12,13].

Despite the aggressive nature of TNBC, $20 \%$ of patients achieve a pCR after NACT [14]. However, TNBC patients who did not achieve pCR are more likely to suffer an early recurrence and die from metastatic disease. The differences in clinical outcomes following neo-adjuvant treatment imply that a subset of TNBCs is sensitive to CT, while the majority become resistant during treatment or are intrinsically less susceptible. Both mechanisms are likely present in the tumors. However, in early, operable TNBC, the administration of CT before (neoadjuvant) rather than soon after surgery (adjuvant) was considered an optional strategy. Therefore, the role of $\mathrm{pCR}$ as a treatment endpoint and a guide for further treatment decisions is considered crucial, and it becomes not an option but rather the preferred treatment strategy for TNBC breast cancer patients [15]. 


\subsection{Adjuvant Setting}

Current guidelines recommend as preferred regimens: doxorubicin (or epirubicin)cyclophosphamide combination (dose dense or every three weeks) followed or not by paclitaxel; docetaxel-cyclophosphamide combination; and cyclophosphamide-methotrexate5-fluorouracil (CMF) combination. Recently, the CREATE X clinical trial showed that, in TNBC breast cancer patients, postsurgical capecitabine can improve prognosis when the disease persists after NACT [12,13].

\subsection{Metastatic Setting}

The main drugs used in this setting include anthracyclines, platinum compounds, taxanes, capecitabine, gemcitabine, vinorelbine, eribulin; sacituzumab govitecan; bevacizumab; olaparib and talazoparib for BRCA1/2 germline mutations carriers; addition of atezolizumab or pembrolizumab to chemotherapy for pogrammed death ligand 1 (PD-L1) overexpressing cancer patients; larotrectinib and entrectinib for neurotrophic tropomyosin receptor kinase (NTRK) gene fusion carriers [12,13].

\section{Main Mechanisms Responsible for Chemoresistance}

$\mathrm{CT}$ resistance represents a main obstacle for successful cancer treatment, especially in the metastatic setting where it accounts for $90 \%$ of therapy failure [16]. In the last decade, numerous mechanisms were uncovered that can lead to the development of chemoresistance. These include cancer stem cells (CSCs) induction after NACT, ATPbinding cassette $(\mathrm{ABC})$ transporters, hypoxia and avoidance of apoptosis, tyrosine kinase receptors (EGFR, IGFR1), a disintegrin and metalloproteinase 10 (ADAM10), noncoding RNAs, DNA methylation, and phosphoproteome, including phosphorylation of kinases and a few pathological molecular pathways.

\subsection{CSCs Induction after NACT}

In solid tumors, CSCs represent a subpopulation with self-renewal properties, that can re-establish a tumor following treatment. In breast cancer, an increase in CSCs was found in residual tumor specimens following CT $[17,18]$. This finding suggests that breast CSCs are resistant to treatment; moreover, their selective survival may lead to a residual tumor enriched in tumor-initiating cells. Accordingly, a high percentage of CSCs in primary breast tumors following NACT was found [19]. TNBC seems to be enriched in CSCs as compared with that of other subtypes [20,21]. Some data seem to support the importance of CSCs in TNBC behavior and prognosis. For example, a positive correlation between the expression of stem cell markers (CD44, ALDH1) and poor survival was found [22,23]. Chemoresistant CSCs may be important in TNBC relapse. In TNBC biopsies carried out following CT, upregulation of RNA transcripts of CSCs associated genes was found [24]. Treatment of TNBC cells with gemcitabine or paclitaxel stimulated the expression of hypoxia-inducible factors (HIFs), as well as the increase in CSCs population and ABCB1 expression [25]. Mechanisms responsible for CSC chemoresistance are still unclear. CSCs are relatively quiescent as compared to that of other cancer cells, and this behavior could be a defense against cytotoxic agents that are generally most effective against proliferating cells [17]. Moreover, CSCs have high ABC transporters expression, mostly ABCG2, which confers resistance to many cytotoxic agents $[26,27]$.

\subsection{ABC Transporters}

Transporter-mediated drug efflux is one of the most studied mechanisms of chemoresistance. $\mathrm{ABC}$ transporters are integral membrane proteins responsible for the ATP-powered translocation of various compounds across cellular membranes, including many anticancer drugs [28]. Multidrug-resistant protein-1 (ABCC1/MRP1), breast cancer resistance protein (ABCG2/BCRP) and multidrug-resistant protein-8 (ABCC11/MRP8) are significantly more expressed in TNBC as compared to that of other subtypes [29]. It was observed that NACT increased ABCC1 protein expression in TNBC [30]. In addition, TNBC cell 
activation of the hedgehog pathway increased drug resistance through upregulation of $A B C$ transporters [31]. ABCG2 is involved in TNBC CSCs, and its downregulation increased chemosensitivity in TNBC cells [26,32]. ABCC1 confers resistance mainly to anthracyclines, taxanes, mitoxantrone, and methotrexate; $\mathrm{ABCG} 2$ transports 5-Fluorouracil, methotrexate, doxorubicin, irinotecan, mitoxantrone, and other drugs [28]. ABCC11 confers resistance to 5-Fluorouracil and methotrexate [33]. In conclusion, ABCC1, ABCG2, and ABCC11 have a wide and overlapping substrate specificity and may confer resistance to the principal antiblastics used in the current TNBC treatment.

\subsection{Hypoxia}

As the tumor expands, blood vessels randomly grow and are often cut-off or destroyed. Low oxygen levels lead to HIFs stabilization; HIFs regulate transcription of genes involved in cell survival in hypoxic conditions. Hypoxia is an important feature of the tumor microenvironment (TME) and is associated with aggressiveness, invasiveness, and resistance to therapy [34]. Hypoxia contributes to chemoresistance in multiple different ways: firstly, insufficient vasculature hinders drug penetration [34]; in addition, the acidic TME due to hypoxia reduces the uptake of anticancer drugs [35]; cytotoxic effects of drugs are often oxygen dependent [36]; hypoxia induces the CSC phenotype [37]; hypoxia activates immunosuppressive pathways and acts as a barrier to immune effector cells, thereby modulating antitumor immunity [38]; hypoxia leads to cellular adaptations that hinder a successful treatment, for example, increased expression in ABC transporters, and decreased proliferation; modulation of apoptosis, induction of autophagy, genetic instability, and subsequent selection of aggressive phenotypes, upregulation of proangiogenic factors, and repression of E-cadherin [36,39-41]. Morphological features typical of hypoxia, for example, fibrotic and necrotic areas, are frequently present in TNBC specimens [42]. Moreover, a study showed that the expression of carbonic anhydrase IX (CAIX), a key HIF-1 regulated gene, was associated with TNBC subtype and shorter survival [43].

\subsection{Avoidance of Apoptosis}

Apoptosis is a key biological process largely dysregulated in cancer disease and evasion of apoptosis takes part of the main cancer hallmarks. Evasion of apoptosis also was reported to be responsible of resistance to different cytotoxic agents, such as paclitaxel, doxorubicin, and cyclophosphamide [44]. The role of apoptotic dysfunction in TNBC prognosis is well documented. For example, expression of pro-survival factors, such as Bcl-2 and Mcl-1, was found to be related to unfavorable outcome [45,46]. In addition, MCL-1 gene is frequently altered in residual TNBCs after CT [47]. A link between Mcl-1 expression and chemoresistance was reported [48]. So, Mcl-1 expression likely contributes to TNBC chemoresistance [45].

\subsection{Receptor Tyrosine Kinases}

Multiple biological processes are due to different growth factors using PI3K-AKTmTOR (PAM) and janus kinase (JAK)/signal transducer and activator of transcription (STAT) signaling pathways. EGFR and IGF-1R, which are part of the receptor tyrosine kinase family, are the upstream regulators of these pathways implicated in TNBC chemoresistance.

\section{EGFR, IGF-1R}

EGFR overexpression in TNBC ranges from $13-76 \%$ and is higher than in other breast cancer subtypes [6]. EGFR gene amplification correlates with protein expression and seems to be the most crucial mechanism behind increased EGFR expression in TNBC [49]. The EGFR pathway is involved in the regulation of ABCG2 expression and function [50]; in fact, EGFR inhibition led to the reversal of ABCG2-mediated chemoresistance in in vitro and tumor models [51]. EGFR pathway is also involved in angiogenesis, cell proliferation, metastatic spread, and inhibition of apoptosis [51]. Insulin-like growth factors (IGFs) binding to their receptor results in proliferation, expression of $\mathrm{ABC}$ transporters, angiogenesis 
stimulation and inhibition of apoptosis [52]. Expression of IGF-1R in TNBCs was found in up to $46 \%$ of cases and was associated with poor survival [53]. It was observed that IGF-1 interacts with the wingless and Int1 (Wnt)/beta-catenin pathway and is overexpressed CSCs in TNBC [54]. Beta-catenin inhibition reduced IGF-1 levels, and this led to decreased CSCs proliferation [54]. IGF-1R overexpression is linked to chemoresistance in various types of cancer [52]. Finally, it was found that IGF-1R was overexpressed in breast tumors following NACT and was associated with shorter OS [55]. These findings are summarized in Figure 1.

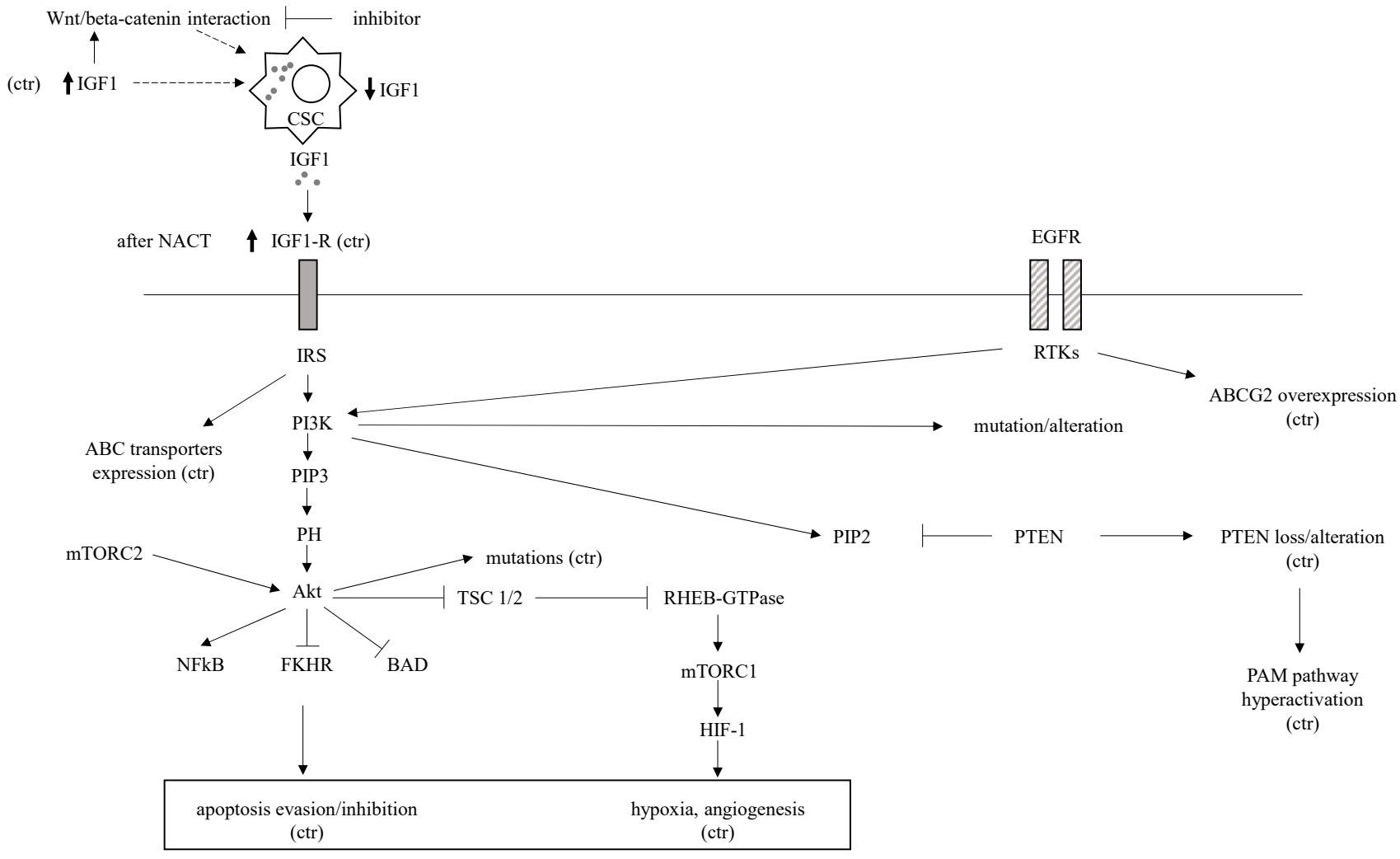

Figure 1. EGFR, IGF1-R, and PI3K-Akt-mTOR (PAM) pathway. Potential mechanisms of chemotherapy resistance (ctr) in TNBC. PI3K activation produces PIP3 from PIP2 substrate; Akt activation inhibits TSC, which acts as a GTPase activating protein for RHEB; mTORC1 induces hypoxia and angiogenesis via modulation of HIF-1; mTORC2 promotes apoptosis evasion/inhibition through NFkB, FKHR, and BAD; PTEN and TSC are significant tumor suppressors. IGF1: insulin growth factor 1; IGF1-R: insulin growth factor 1 receptor; CSC: cancer stem cell; NACT: neoadjuvant chemotherapy; EGFR: epidermal growth factor receptor; RTKs: receptors with protein tyrosine kinase activity; PIP2: phosphatidylinositol-4,5 biphosphate; PIP3: phosphatidylinositol-3,4,5 triphosphate; PH: protein with pleckstrin homology; Akt: protein kinase B; GTPase: guanosine triphosphatase; HIF-1: hypoxia

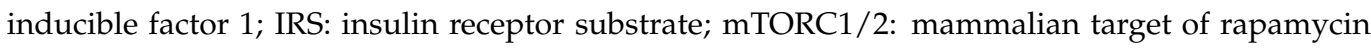
complex 1/2; PI3K: phosphatidylinositol 3 kinase; PTEN: phosphatase and tensin homolog deleted on chromosome 10; TSC: tuberous sclerosis; RHEB: RAS homolog enriched in brain (GTP-binding protein); FKHR: forkhead family transcriptor factors; ABC: ATP binding cassette; ABCG2: ATP binding cassette superfamily G member 2; NFkB: nuclear factor kappa-high chain enhancer of activated B cells; BAD: Bcl-2 associated death promoter. $\uparrow$ increase; $\downarrow$ decrease. Also see text.

\subsection{A Disintegrin and Metalloproteinase 10 (ADAM10)}

One study investigated the potential roles of ADAM10 on TNBC cells and the effects of combining ADAM10 expression and NACT to improve the OS in breast cancer patients. Knockdown of ADAM10 in MDA-MB-231 cells led to a significant decrease in cell proliferation, migration, invasion, and the IC50 value of paclitaxel and adriamycin, while also 
inducing cell cycle arrest and apoptosis. These changes were correlated with downregulation of Notch signaling, CD44, and cellular prion protein (PrPc). Immune-histochemical staining for ADAM10 in breast cancer tissues of 94 patients receiving NACT also was performed. A high ADAM10 expression in pre-NACT samples was strongly associated with poorer response to NACT and shorter OS. These data suggest that ADAM10 plays an important role in contributing to the progression and chemoresistance of TNBC [56].

\subsection{Noncoding RNAs, DNA Methylation, and Phosphoproteome including Phosphorylation of Kinases}

Epigenetic remodeling through noncoding RNAs of gene expression profiles and alterations of DNA methylation play a central role in the pathogenesis, maintenance, and therapeutic resistance of TNBC. NcRNAs constitute about $98 \%$ of the genome, and others include microRNAs (miRNAs), long noncoding RNAs (lncRNAs), and circular RNAs (circ RNAs) [57]. In recent years, despite these RNAs not coding proteins, a lot of data supported the central role of miRNAs and lncRNAs in chemoresistance by governing different genes and molecular pathways. When gene is the target, they function as oncogenes or tumor suppressor genes to lastly induce or inhibit chemoresistance. Aberrant expression of miRNAs and lncRNAs and subsequent promotion of apoptotic resistance, EMT, TME disorder, and $\mathrm{ABC}$ transporters upregulation are some modalities by which both these ncRNAs favor the occurrence of chemoresistance. Additionally, aberrant expression of miRNAs can promote cell cycle arrest, CSCs, DNA repair, autophagy inhibition, and thereafter, chemoresistance. CircRNAs interact with miRNAs, thus providing a novel mechanism to promote chemoresistance. Namely, it was shown that circCDR1as induces chemoresistance to 5-FU in TNBC by inhibiting miRNA-7 and successively governing cyclin E1 (CCNE1), while circKDM4C, which is downregulated in DOX resistant TNBC cells, favors DOX resistance by inhibiting cell cycle and apoptosis; this inhibition promotes the oncogenic action of miRNA548p, and subsequently, PBLD (phenazine biosynthesis-like domain containing protein) degradation [58].

DNA methylation is governed by the balance of DNA methylases (DNMTs) and DNA demethylases (TETs), and TNBCs are characterized by strong hypomethylation and lower gains of methylations compared to that of all other subtypes. In a study [59], whole-genome DNA methylation profiling on diagnostic TNBC biopsy samples from the Sequential Evaluation of Tumors Undergoing Preoperative (SETUP) NACT study was carried out. At the time of diagnosis, nine significantly differentially methylated regions (DMRs) were associated with response to NACT, and four of them also were associated with TNBC OS $(p<0.05)$. In another investigation [60], the percent DNA methylation ratio (PMR) of paired-like homeodomain transcription factor 2 (PITX2) was assessed by a validated methylation-specific real-time PCR test. Tissue samples and clinical data from 66 untreated and 78 TNBC patients treated with anthracycline-based CT were analyzed. PITX2 DNA methylation with a PMR cutoff of two did not show significance for poor vs. good outcomes $(\mathrm{OS})$ in the untreated patient cohort $(\mathrm{HR}=1.55 ; p=0.259)$. By contrast, the PITX2 PMR cutoff of two identified patients with poor (PMR $>2)$ vs. good $(\mathrm{PMR} \leq 2)$ outcomes (OS) with statistical significance in the anthracycline-treated cohort $(\mathrm{HR}=3.96$; $p=0.011$ ). In a further recent study [61] conducted on TNBC, five differentially methylated sites (DMSs) signatures with good performance for the prediction of DFS and OS were constructed.

Activation of protein kinases and phosphatases through phosphorylation is involved in signal transduction, and the basal level of the phosphoproteins is a main feature of the cell. In a study [62], high-throughput technology was used to evaluate changes in phosphorylated proteins to identify relevant pathways involved in TNBC chemoresistance. Four resistant and two sensitive to docetaxel, doxorubicin, gemcitabine, and cisplatin cell lines were selected among 12 TNBC cell lines. A total of 1340 phosphoprotein groups, 2760 unique phosphopeptides, and 4549 unique phosphosites were defined. It was found that differentially phosphorylated cyclin-dependent kinase (Cdk) 5, promyelo- 
cytic leukemia protein (PML), protein 1(AP-1) transcription factor, and heat shock factor 1 (HSF-1) might collaborate to promote EMT in the drug-resistant cells, with EGFR and hormone growth factor (HGF) likely involved in this process. In the human genome there are about 538 kinase genes [63] and aberrant expression or activation of protein kinases also may be implicated in drug resistance. In a study, MDA-MB-231 cells were used to monitor cell viability and were screened with a kinome siRNA library to identify potential drug resistance kinases in TNBC cells treated with CT. Genetic or pharmacological ablation of the Src kinase decreased the phosphorylation of AKT and STAT3 and increased the sensitivity of TNBC cells to chemotherapeutic drugs. Concomitant overexpression of Src and STAT3 was associated with poor prognosis in TNBC patients. Authors concluded that Src inhibitor combined with chemotherapeutic drugs might be beneficial in Src-expressing TNBC patients $[64,65]$.

\subsection{Pathological Molecular Pathways \\ 3.8.1. TGF-Beta Pathway}

Tumor growth factor (TGF)-beta takes part of a large cytokine superfamily that encompass over 30 related growth factors, including three TGF-beta isoforms (TGFbeta-13) [66]. EMT, proliferation, angiogenesis, metastatic spread, CT resistance, and immunomodulation are described effects of TGF-beta signaling [67]. Besides, the TGF-beta pathway plays a crucial role for the regulation of breast CSCs [68]. In TNBC, it was reported that CT enhanced TGF-beta signaling [24]. Furthermore, a TGF-beta-R inhibitor in TNBC xenografts impeded the re-establishment of tumors following CT [24]. Both TGF-beta overexpression and elevated breast CSC markers were found in epirubicin-resistant TNBC cell lines [69].

\subsubsection{Notch Pathway}

The Notch signaling pathway comprehends four cell surface receptors (NOTCH 1-4) and five trans-membrane ligands (Delta-like 1,3,4 and JAGGED-1,2). Notch 1-4 signaling plays a key role for the maintenance of breast CSCs and significantly correlates with resistance to CT [70]. In breast cancer cell lines, Notch-1 signaling induced by doxorubicin promoted ABCC1 overexpression. Conversely, gamma-secretase inhibitor (GSI) reverted the Notch-1 induced ABCC1 overexpression, and thus the cells became more susceptible to doxorubicin [71]. This effect also occurred in TNBC cells, where GSI increased the efficacy of doxorubicin [72]. Consistent with these findings, Notch-1 inhibitors synergized with docetaxel in TNBC and had robust antitumor action in breast CSCs and patient-derived xenograft models [73].

\subsubsection{Wnt/Beta-Catenin Pathway}

Wnt signaling likely promotes tumor initiation, stemness, and metastatic spread [74,75]. In the lack of Wnt, beta-catenin quickly deteriorates following the action of the multiprotein destruction complex. Binding of Wnt to its receptors and co-receptors (Frizzled and low-density lipoprotein receptor-related proteins (LRP5/6), respectively) dissolves the destruction complex stabilizing beta-catenin. Accordingly, TNBC cells with knockeddown beta-catenin are highly susceptible to CT and form significantly smaller tumors in murine models. Wnt/beta-catenin signaling knock-down decreased the TNBC stem cell population [76]. Beta-catenin synergized with NIMA related kinase 2 (Nek2B) regarding CT resistance in TNBC [77]. An upregulation of other components of the Wnt/beta-catenin pathway was also found in TNBC, while FZD8-mediated Wnt signaling that was significantly enhanced in residual cells after NACT had a major role in TNBC chemoresistance [78]. The potential mechanisms of CT resistance are schematically shown in Figure 2. 


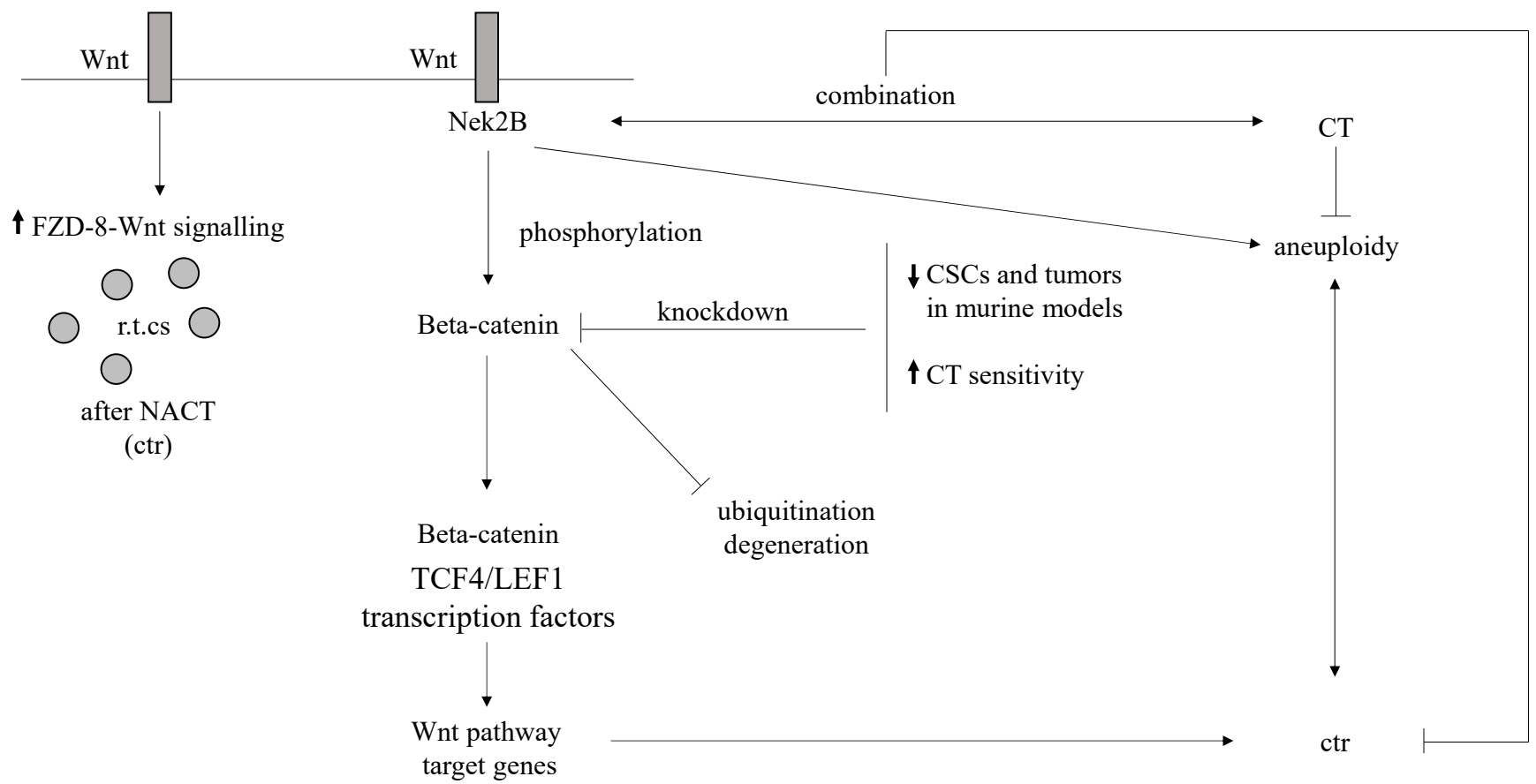

Figure 2. Wnt-beta-catenin pathway. Potential mechanisms of chemotherapy resistance (ctr) in TNBC. FZD-8: Frizzled-8; NEK2B: NIMA related kinase 2; CSCs: cancer stem cells; CT: chemotherapy; TCF: T cell factor; LEF: lymphocyte enhancer factor; r.t.cs: residual tumor cells; NACT: neoadjuvant chemotherapy. $\uparrow$ increase; $\downarrow$ decrease. Also see text.

\subsubsection{Hedgehog (Hh) Pathway}

The Hh signaling pathway is a crucial network for embryogenesis and tissue regeneration. The Hh pathway includes three secreted ligands, of which the Sonic Hedgehog (SHH) is the most widely expressed, followed by trans-membrane receptor/co-receptors Patched $(\mathrm{PTCH})$ and Smoothened (SMO). Activated SMO originates the full-length activator form of GLI transcription factors-GLIA. Three glioma-associated oncogene transcription factors (GLI1-3) are the principal effectors, and GLIAs, after they have moved to the nucleus, govern the expression of many target genes, such as ABCG2 and VEGF (vascular endothelial growth factor) [79]. GLI1/2 are associated with cell survival, proliferation, invasion, EMT, angiogenesis, and chemoresistance in different human tumors [80]. Growing evidence suggests relationship of Hh signaling with more clinical aggressiveness of TNBC and Hh signaling is also strongly linked with CSC in TNBC. While both GLI1 and GLI2 are overexpressed in breast CSCs, cell differentiation significantly decreased their expression [81]. Hh signaling association with larger tumor size, high grade, high stage, and with poor prognosis in TNBC was reported [82]. In breast cancer cell lines, docetaxel treatment activated Hh signaling that increased survival and expanded breast CSC [81]. After exposure of malignant cells to cytotoxic drugs, GLI1 was overactivated via noncanonical pathway and, successively, promoted the ABC transporters upregulation [31].

\subsubsection{NF-kB Pathway}

NF-kB (nuclear factor kappa-light-chain-enhancer of activated B cells) family comprehends five members that can give origin to hetero- and homodimers [83]. NF-kB is strongly overexpressed in TNBC compared to that of normal breast tissue [84], and NF-kB activation promotes chemoresistance in breast and other types of cancer [83]. NF-kB signaling is also upregulated by hypoxia, which has a clear connection with chemoresistance [85]. In a recent report, it was found that apatinib sensitizes doxorubicin-resistant breast cancer cells to doxorubicin, which is accompanied by significantly increased apoptosis. The increased induction of apoptosis was associated with reactive oxygen species (ROS) accumulation, 
likely through the inhibition of NF- $\mathrm{BB}$ signaling pathways, which were showed to increase ROS production and reverse doxorubicin-resistance. Moreover, the combination of doxorubicin and apatinib resulted in increased antitumor effects on TNBC cell xenograft models [86]. Figure 3 shows the role of NFkB pathway in CT resistance in TNBC.

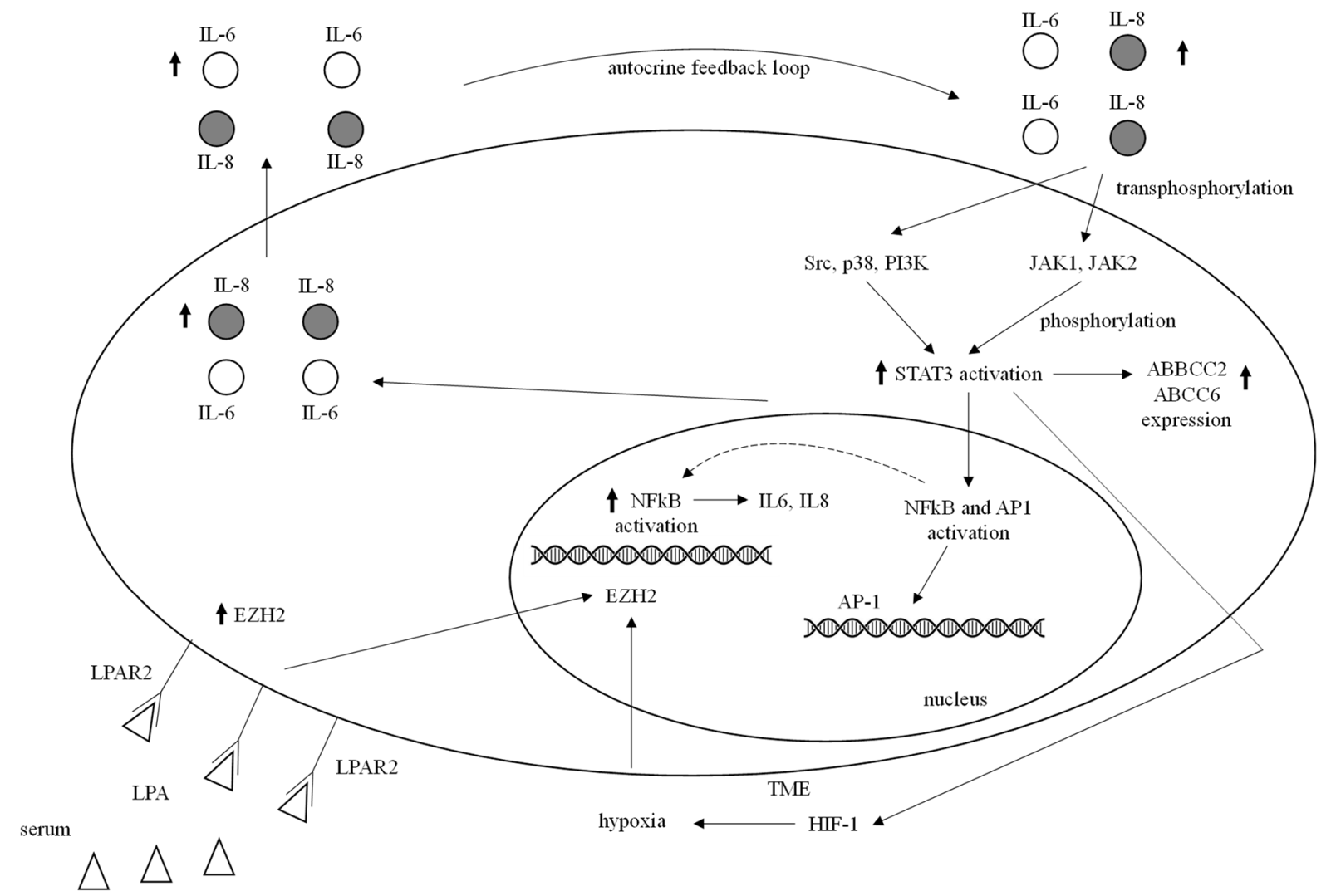

Figure 3. NFkB and JAK/STAT pathways. Potential mechanisms of chemotherapy resistance (ctr) in TNBC. NFkB is upregulated by hypoxia and activated through LPA-LPAR-EZH2-NFkB signaling cascade which results in autocrine production of IL-6 and IL-8. Extracellular IL-6, IL-8 ligand permits transphosphorylation of JAKs that successively phosphorylate STAT monomers. Activated STAT3 enters nucleus, where it governs transcription of many target genes; activated STAT3 also induces upregulation of ABCC2 and ABCC6, and therefore IL- 6 and IL- 8 by multiple pathways induce tumor growth, resistance to apoptosis, and chemotherapy resistance. LPA: lysophosphatidic acid; LPAR: LPA receptor; EZH2: enhancer of zeste homolog 2 (a gene component of polycomb repressive complex (PRC2) and epigenetic regulator); TME: tumor microenvironment; IL: interleukin; NFkB: nuclear factor kappa-high chain enhancer of activated B cells; STAT: signal transducer and activator of transcription; Src: Src family kinase; p38: p38 mytogen-activated protein kinase; PI3K: phosphatidylinositol 3 kinase. $\uparrow$ increase. Also see text.

\subsubsection{PTEN and PI3K-AKT-mTOR Pathway}

PAM pathway is frequently hyperactivated in TNBC, mainly due to the negative regulator tumor suppressor phosphatase and tensin homolog (PTEN) loss, and is associated with adverse clinical course, aggressive tumors, and poor outcome [87-89]. In TNBC, approximately $10 \%$ of patients have an activating mutation in PIK3CA and $30-50 \%$ with PTEN alterations [87]. Different subtypes of TNBC have specific phosphoinositide 3kinase (PI3K) pathway mutations/alterations; for example, PIK3CA and AKT1 mutations are more likely to be found in AR-positive TNBC [87]. PTEN loss also contributes to chemoresistance of breast cancer [90]. In addition, AKT induces HIF-1, which is a notable factor in chemoresistance [88] (Figure 1). 


\subsubsection{JAK/STAT Pathway}

The JAK/STAT pathway encompasses four cytoplasmic proteins with Janus kinase domain (JAK1-3, TYK2) and seven proteins that comprise the signal transducer and activator of transcription protein family (STAT1-4, STAT5A, STAT5B, and STAT6). Extracellular interleukin (IL) 6, IL8 ligand allows the trans-phosphorylation of JAKs which then phosphorylate STAT monomers. Activated STATs enter the nucleus and subsequently govern the transcription of several target genes [91]. In TNBC, genetic profiling uncovered a proinflammatory gene signature including IL6 and IL8 genes [92]. Combined inhibition of IL6 and IL8 significantly induced apoptosis, and increased TNBC sensitivity to paclitaxel [92]. STAT3, a member of the JAK/STAT signaling pathway downstream from IL6/8, is overexpressed in TNBC and linked with tumor initiation, clinical aggressiveness, unfavorable outcome, and resistance to CT $[93,94]$. STAT3-NF-kB interaction and collaboration account for chemoresistance in TNBC [95]. Furthermore, STAT3 was upregulated in TNBC stem cells resistant to doxorubicin [96]. STAT3 was also involved in hypoxia-mediated chemoresistance in TNBC through HIF1 upregulation. Interestingly, STAT3 further contributed to hypoxia-induced chemoresistance by upregulation of $A B C$ transporters expression [97] (Figure 3).

The principal reasons likely responsible for chemoresistance in triple-negative breast cancer are summarized in Table 1.

Table 1. Principal reasons likely responsible for chemoresistance in triple-negative breast cancer (TNBC).

\begin{tabular}{|c|c|c|c|}
\hline $\begin{array}{l}\text { Biological Condition/ } \\
\text { Component }\end{array}$ & Status & Mechanism & References \\
\hline Cancer stem cells & $\begin{array}{l}\text { Intrinsically enriched, increased } \\
\text { after NACT through HIFs and } \\
\text { ABC B1 upregulation }\end{array}$ & $\begin{array}{c}\text { Quiescence, ABCG2 transporter } \\
\text { overexpression, tumor-initiating cells } \\
\text { enrichment }\end{array}$ & [17-27] \\
\hline ABC Transporters & $\begin{array}{c}\text { ABCC1/MRP1, ABCG2/BCRP, } \\
\text { ABCC11/MRP8 intrinsic increase } \\
\text { or after NACT or Hh pathway }\end{array}$ & Transporter-mediated efflux through ATP & [29-33] \\
\hline Hypoxia & $\begin{array}{l}\text { Morphological features } \\
\text { characteristics of hypoxia } \\
\text { (expression of CAIX) }\end{array}$ & $\begin{array}{l}\text { Insufficient drug penetration and multiple } \\
\text { other mechanisms due to the promoted } \\
\text { TME changes (see text) }\end{array}$ & [34-43] \\
\hline Apoptosis & $\begin{array}{l}\text { Malfunction (BCL-2 and Mcl-1 } \\
\text { protein expression) }\end{array}$ & Evasion of apoptosis & [44-48] \\
\hline \multicolumn{4}{|c|}{ Factor } \\
\hline EGFR & $\begin{array}{l}\text { Increased expression (from } 13 \% \\
\text { to } 76 \% \text { ) }\end{array}$ & $\begin{array}{c}\text { ABCG2-mediated, apoptosis inhibition, } \\
\text { angiogenesis, and cell proliferation } \\
\text { involvement }\end{array}$ & {$[6,49-51]$} \\
\hline IGF-1R & $\begin{array}{l}\text { Expressed in } 46 \% \text { and increased } \\
\text { after NACT }\end{array}$ & $\begin{array}{l}\text { ABCG2-mediated, apoptosis inhibition, } \\
\text { angiogenesis and cell proliferation } \\
\text { involvement, Wnt-beta-catenin interaction, } \\
\text { CSCs self-renewal decrease }\end{array}$ & [52-55] \\
\hline ADAM10 & Highly expressed in cell lines & $\begin{array}{l}\text { Notch signaling downregulation; } \\
\text { proliferation, migration, invasion increase }\end{array}$ & [56] \\
\hline NcRNAs & Aberrant expression & $\begin{array}{c}\text { Promotion of apoptosis resistance, EMT, } \\
\text { ABC transporters upregulation; cell cycle } \\
\text { arrest, CSCs, DNA repair and autophagy } \\
\text { inhibition }\end{array}$ & {$[57,58]$} \\
\hline DNA methylation & $\begin{array}{l}\text { Strong hypomethylation and low } \\
\text { gains of methylation }\end{array}$ & $\begin{array}{c}\text { Significantly differentially methylated } \\
\text { regions }\end{array}$ & [59-61] \\
\hline
\end{tabular}


Table 1. Cont.

\begin{tabular}{|c|c|c|c|}
\hline $\begin{array}{l}\text { Biological Condition/ } \\
\text { Component }\end{array}$ & Status & Mechanism & References \\
\hline $\begin{array}{c}\text { Phosphoproteome, } \\
\text { phosphorylation of kinases }\end{array}$ & $\begin{array}{l}\text { Activation of protein kinases and } \\
\text { phosphatases through } \\
\text { phosphorylation }\end{array}$ & $\begin{array}{l}\text { Changes in phosphorylated proteins, } \\
\text { phosphorylation and signal transduction } \\
\text { involvement, aberrant expression or } \\
\text { activation of protein kinases }\end{array}$ & {$[62]$} \\
\hline \multicolumn{4}{|c|}{ Pathologic Molecular Pathway } \\
\hline TGF-beta & Signaling increase after NACT & CSCs upregulation, EMT increase & {$[24,66-69]$} \\
\hline Notch & Signaling increase after NACT & CSCs maintenance, ABCC1 overexpression & [70-73] \\
\hline Wnt/beta-catenin & Signaling deregulation & $\begin{array}{l}\text { CSCs increase, beta-catenin synergistic } \\
\text { effect with NeK2B FLD8-mediated } \\
\text { signaling increase }\end{array}$ & [74-78] \\
\hline Hedgehog (Hh) & $\begin{array}{c}\text { Signaling activation by cytotoxic } \\
\text { drugs }\end{array}$ & $\begin{array}{c}\text { CSCs expansion through GLI1/2 activation, } \\
\text { promotion of expression of ABC } \\
\text { transporters }\end{array}$ & {$[31,79-82]$} \\
\hline NF-kB & Overexpression & Apoptosis inhibition & [83-86] \\
\hline $\begin{array}{l}\text { PTEN and PI3K-AKT-mTOR } \\
\text { (PAM) }\end{array}$ & Hyperactivation due to PTEN loss & PTEN loss, HIF-1 induction by Akt & [87-90] \\
\hline JAK/STAT & $\begin{array}{l}\text { STAT3 hyperexpression } \\
\text { downstream of IL-6/8 } \\
\text { extracellular ligands }\end{array}$ & $\begin{array}{l}\text { STAT3-NFkB interaction, STAT3 HIF-1 and } \\
\text { ABC transporters expression upregulation }\end{array}$ & [91-97] \\
\hline
\end{tabular}

TNBC: triple negative breast cancer; CSCs: cancer stem cells; NACT: neoadjuvant chemotherapy; HIFs: hypoxia inducible factors; ABC: ATP binding cassette; MRP1: multidrug-resistant protein-1; BCRP: breast cancer resistance protein; CAIX: carbonic anhydrase IX; TME: tumor microenvironment; Bcl-2: B-cell lymphoma 2; Mcl-1: myeloid cell leukemia-1; EGFR: epidermal growth factor receptor; IGF1R: insulin growth factor 1 receptor; Wnt: wingless and Int 1; ADAM-10: a disintegrin and metalloproteinase-10; NcRNA: non coding RNA; TGF-beta: tumor growth factor-beta; EMT: epithelial-to-mesenchymal transition; Nek2B: NIMA-related kinase 2B; FZD8: frizzled-8; GLI: glioma-associated oncogene transcription factors; NFkB: nuclear factor kappa light chain enhancer of activated B cells; PTEN: phosphatase and tensin homolog; PI3K: phosphoinositol-3 kinase; Akt: akr mouse strain thymoma; mTOR: mammalian target of rapamycin; JAK: janus kinase; STAT: signal transducer and activator of transcription; IL: interleukin.

\section{Prediction of Resistance to Chemotherapy in TNBC}

$\mathrm{CT}$ is the mainstay of TNBC treatment and chemoresistance is a hurdle in neoadjuvant as well as in the metastatic settings. Histology and tumor-infiltrating lymphocytes (TILs) provide useful information in predicting resistance to $\mathrm{CT}$.

\subsection{Histology and Molecular Subtype}

Some studies reported a worse prognosis for metaplastic carcinoma, a rare, aggressive subtype of breast cancer associated with poorer OS than that of other TNBCs [98]. Particularly, the squamous subtype had the worst survival [99]. Metaplastic breast cancer, which was also reported as poorly responsive to neoadjuvant treatment [100], frequently expresses immune checkpoint markers forkhead box P3 (FOXP3) and PD-L1 and may benefit from immune-based therapies [101]. The principal TNBC subtypes [10,102,103] display varying levels of chemoresistance, which is reflected in their pCR rates after NACT [104]. The luminal androgen receptor (LAR) subtype is the most resistant subtype based on the information received from several clinical trials and preclinical studies [104,105]. It was observed that LAR tumors are relatively quiescent, which could partially explain their chemoresistance [106]. After LAR, the lowest $\mathrm{PCR}$ rates were observed in mesenchymal (MES) tumors [104]. TNBC cell cultures with mesenchymal properties, such as MDA-MB231 and hs578t, display high levels of chemoresistance. The MES subtype of TNBC is enriched in gene expression signatures linked with EMT and stemness. The basal-like (BL1 and 2) group demonstrates high $\mathrm{pCR}$ rates; it is characterized by robust proliferation and is enriched in genes involved in cell cycle and DNA damage response [102]. BRCA1/2 is 
frequently inactivated in BL1 subtype due to mutations or hyper-methylation. This leads to deficiencies in DNA damage repair, thus making these tumors more susceptible to DNA damaging agents [102].

\subsection{Tumor Infiltrating Lymphocytes (TILs) and Neoadjuvant Response}

TILs predict the NACT efficacy pre-, post-, or during treatment in the different molecular subtypes, mostly in TNBC. In the neoadjuvant setting, studies underlined the relevance of TILs evaluation for predicting PCR and TILS rate significantly correlated with a better TNBC and HER2-positive breast cancer prognosis [107]. In a study carried out in 1058 patients, in those with TIL infiltration more than 10\% following neoadjuvant anthracycline/taxane-based CT, pCR rate was $40-42 \%$ compared to only $3-7 \%$ in patients with tumors with low TIL infiltration. Elevated TIL infiltration in TNBC correlated directly with pCR after neoadjuvant anthracycline CT alone, taxane-based regimens alone, and anthracycline and taxane sequentially or concurrently administered [108]. Similarly, an association between high TILs and PCR in a group of TNBC patients receiving paclitaxel followed by a combination of fluorouracil, epirubicin, and cyclophosphamide (FEC) occurred [109]. Recently, the international TILs Working Group, renamed the "International Immuno-Oncology Biomarker Working Group on Breast Cancer" elaborated an integrated survival prediction model for patients with early-stage TNBC. The model involved TILs, PD-L1 and Cluster of Differentiation 73 (CD73) expression in a tissue immune profile (TIP) [110]. A TIP positive (TIP+) tumor was any tumor with contemporaneous presence of TILS $\geq 50 \%$, PD-L1 $\geq 1 \%$, and CD73 $\leq 40 \%$. Sixty biopsies from patients with TNBC who received standard NACT were retrospectively examined. pCR was achieved in 23 patients $(38.0 \%), 12(20.0 \%)$ of whom were TIP + . The pCR rate was significantly higher in $\mathrm{TIP}+(91.7 \%)$ than in TIP $-(25.0 \%)(p<0.0001)$, and using a multivariate analysis, TIP was confirmed to be an independent predictive factor of pCR (OR 49.7 (6.30-392.4), $p<0.0001)$. The combined TIP was more accurate than single biomarkers in predicting PCR [111].

\section{TIL Subsets}

The infiltration of CD3+ T cells was reported to predict the response to NACT in breast cancer [112]. In TNBC patients receiving neoadjuvant anthracycline/anthracycline + taxane-based therapy, increased CD4+, CD8+, and FOXP3+ TIL infiltration correlated with pCR [113]. Similarly elevated pCR rates occurred in patients with high infiltration in pretreated biopsies of both FOXP3+ and CD8+ TILs who received neoadjuvant paclitaxel followed by FEC [109]. An increased CD8/FOXP3+ TIL ratio in pretreatment biopsies significantly correlated with PCR in TNBC and HER2-positive breast cancer, following FEC100 and paclitaxel + trastuzumab respectively. CD20+ TIL (B cells) significantly correlated with pCR and CD20 overexpression joined with a 5.5 times likelihood of a pCR to a neoadjuvant anthracycline + taxane combination [105]. A significant decrease in cytotoxicity of circulating natural killer (NK) cells was found in tumors poor responsive to NACT [114]. Conversely, a significant increase in NK cells in the peritumoral environment but not in intratumoral NK cells was associated with tumors having a good pathological response. Increased activity of NK cells in the peripheral blood after NACT joined with the disappearance of lymph node metastasis in breast cancer patients [115-118]. In patients with locally advanced breast cancer, elevated pre-NACT circulating neutrophils and their significant decrease concomitant with pCR in axillary lymph nodes with metastatic involvement after eight cycles of capecitabine, docetaxel, adriamycin, and cyclophosphamide neoadjuvant regimens were reported [119]. A significant increase in circulating dendritic cells was found in breast cancer patients whose tumors had a good pathological response after neoadjuvant regimens with adriamycin and cyclophosphamide followed by capecitabine and docetaxel. However, a significant decrease in the intratumoral CD1a + tumor-infiltrating DCs was shown, without any significant association with response to therapy, in both primary breast tumors and metastatic axillary lymph nodes [119]. 


\subsection{Biomarkers Helpful in Predicting Chemoresistance}

In TNBC management, molecular testing can identify many different biomarkers capable to predict chemoresistance in general or chemoresistance to specific commonly used chemotherapeutic agents. They include BRCAness and deoxyribonucleic acid (DNA) homologous recombination deficiency (HRD), lnc RNAs, micro RNAs, circular RNAs, C-XC motif chemokine ligand 8 (CXCL8)- C-X-C motif chemokine receptor (CXCR) $1 / 2$ axis, different molecules (nuclear protein 10 (NOP10), ceramide kinase (CERK), transmembrane protease, serine 13 (TMPRSS13), tripartite motif containing 37 (TRIM37), MEF2-interacting transcriptional repressor (MITR), synaptotagmin-like 4 (SYTL4), nod-like receptor protein 3 (NLRP3), single genes (protocadherin 17 gene (PCDH17) and jumonji and AT-rich interaction domain containing 2 (JARID2)), or clusters of genes. Clinical trials that address the interaction between biomarkers and treatment approaches are necessary to tailor therapy in TNBC [120].

\subsubsection{Biomarkers Predicting Resistance to Platinum-Based Therapy}

Lnc DLX6-AS1, miR-105, miR-93-3p, 321 miRNAs including miR-34a, BRCAness, and HRD were reported to account for resistance to platinum-based therapy.

Lnc DLX6-AS1, miR-105, miR-93-3p and 321 miRNAs including miR-34a

In a study, overexpression of DLX6-AS1 levels determined by quantitative real-time PCR (RT-qPCR) was found in TNBC tissues and cell lines when compared with that of normal tissues or breast fibroblast cells. Knockdown or upregulation of DLX6-AS1 decreased or increased cisplatin resistance, respectively. Moreover, findings in xenograft experiments using nude mice showed that DLX6-AS1 governed cell proliferation, EMT, and cisplatin resistance by miR-199b-5p/PXN axis [121]. MiR-105 and miR-93-3p induced cisplatin chemoresistance, stemness, and metastasis in TNBC through Wnt/beta-catenin signaling [122]. In a pilot study evaluating bloodborne miRNA signatures from 21 basal-like TNBC cases treated with NACT 321 deregulated miRNAs including miR-34a were reported when comparing expression pre- and post-treatment. Besides after NACT containing paclitaxel and carboplatin, the complete responders had a tendency to have higher miRNA levels [123].

\section{BRCAness and HRD}

$B R C A 1 / 2$ genes code for tumor suppressor proteins involved in DNA repair via homologous recombination therefore they play a critical role in genetic integrity. In particular, $B R C A$ mutations lead to HRD and many patients were reported to harbor HRD [124]. However, HRD can occur in tumors that do not carry BRCA1/2 mutation, defining a subgroup of patients referred to as BRCAness. BRCAness includes a series of traits in which $B R C A 1$ dysfunction following gene mutation, methylation, or deletion accounts for DNA repair deficiency [125]. BRCAness refers to a phenotype common in TNBC that shares molecular characteristics, and the resulting clinical features are similar to those found in $B R C A$-mutated patients [126]. Patients with a BRCAness phenotype have DNA repair failure and different mechanisms, including epigenetic inactivation of $B R C A$ and germline or somatic mutations in other key genes involved in the homologous recombination system such as BARD1, ATR, PALB2, RAD51, RAD51D, ATM, CHK1, PLK1, and WEE1 are responsible [126,127]. An HRD score was elaborated as a tool to further identify TNBC tumors that encompass a BRCAness phenotype occurring in roughly $45-70 \%$ of TNBC [128]. High HRD score is significantly associated with improved $\mathrm{pCR}$ rate with standard NACT in TNBC [129]. Identifying which TNBC tumors have HRD may further define the patients that would benefit from treatment with platinum agents [130]. In two clinical studies the HRD score predicted the likelihood of response to platinum-containing therapy in the neoadjuvant setting $[131,132]$ and tumors with BRCAness may show similar sensitivities to anticancer drugs as tumors with $B R C A 1$ mutations. Another study investigated the association of BRCA mutations or BRCAness with drug sensitivities in TNBC. Namely, BRCAness 
as BRCA1-like score was evaluated in 12 TNBC cell lines, including four with mutations, using multiplex ligation-dependent probe amplification. Sensitivities to docetaxel, cisplatin, and epirubicin were compared with BRCA mutations and BRCA1-like scores. Sensitivity to cisplatin was examined in BRCA1 knockdown MCF-7 cell lines. Eight- and four-cell lines had characteristics of BRCAness and non-BRCAness, respectively. Regarding cisplatin, scores were lower in BRCA mutants and tumors with BRCAness than their counterparts. An inverse correlation was found between BRCA1-like scores and cisplatin sensitivity $(\mathrm{r}=-0.407 ; p=0.013)$ and $B R C A 1$ gene knockdown increased the cisplatin sensitivity of Michigan Cancer Foundation-7 cells. Authors concluded that BRCA1-like scores were associated with cisplatin sensitivity [133].

\subsubsection{Biomarkers Predicting Resistance to Taxanes Alone or with Other Agents}

BRCAness, IL-6, CXCL8, VEGFA, early growth response 1 (EGR1), prostaglandinendoperoxide synthase 2 (PTGS2), and tribbles pseudokinase 1 (TRIB1) signature, CXCL8CXCR1/ 2 axis as well as SYTL4, MITR, serine protease inhibitor clade E member 1 (SERPINE1), tumor necrosis factor ligand superfamily member 13 (TNFS13), miR-5195-3p, miR18a, miR-1207-5p, metastasis-associated lung adenocarcinoma transcript 1 (MALAT1), CERK, transmembrane protease serine 13 (TMPRSS13), PCDH17, and JARID2 factors were reported as predictive biomarkers of resistance to taxanes alone or with other agents.

\section{BRCAness}

In a study, BRCAness was detected in 121 breast cancer patients. Forty-eight patients $(39.7 \%)$ were identified as BRCAness positive. Tumors of BRCAness were more likely to be hormone receptors negative ( $95.8 \%$ vs. $50.7 \%, p<0.001)$, nuclear grade III $(76.1 \%$ vs. $48.4 \%$, $p=0.001)$ and TNBC subtype $(91.6 \%$ vs. $42.5 \%, p<0.001)$. In NACT subgroup analysis, clinical response rate for taxane-based regimen was significantly lower in BRCAness patients $(58.3 \%$ vs. $77.8 \%, p=0.041)$. Authors concluded that BRCAness may suggest resistance to taxane-based CT [134]. Similarly, in the just above-mentioned study [133] the $50 \%$ inhibitory concentration of docetaxel was higher in BRCA mutant and BRCAness cell lines than their counterparts. BRCA1-like scores showed a weak positive correlation with docetaxel sensitivity $(r=0.377 ; p=0.039)$. Authors concluded that BRCA1-like scores were associated with docetaxel resistance.

\section{IL-6, CXCL8, VEGFA, EGR1, PTGS2, TRIB1 Signature and CXCL8-CXCR1/2 Axis}

The implication of paclitaxel in TNBC cell lines after a prolonged administration, and the altered gene expression pattern by microarray technology and validation by qRT-PCR of the resistance to therapy relevant genes were evaluated. Functional assays showed that paclitaxel exhibits antiproliferative activity on Hs578T/Pax and MDA-MB-231/Pax demonstrating the activation of cell death mechanisms. Important alterations at the transcriptomic and genomic levels were observed. Particularly, a common drug resistance signature (IL-6, CXCL8, VEGFA, EGR1, PTGS2 and TRIB1) for both cell lines at 24 passages was discovered. Also, an important mutation (tumor protein 53, TP53) linked with drug response was identified [135].

Another study investigated the prediction value of CXCL8-CXCR1/2 axis for TNBC patients undergone NACT with weekly paclitaxel plus carboplatin. Correlations between variables and treatment response were studied. CXCL8 level was significantly upgraded after NAC in CXCR1/2+ patients and downgraded after NACT in CXCR1/2- patients. Higher pCR rate was more likely observed in patients with lower CXCL8 level at surgery $(p=0.004$, HR $0.939,95 \%$ CI 0.900-0.980). Authors concluded that although further confirmatory studies are needed, these findings suggest that CXCL8-CXCR1/2 might play an important role in tailoring and modifying the NACT strategy for advanced TNBCs [136]. 
SYTL4, MITR, SERPINE1, TNFS13 Factors and miR-5195-3p, miR-18a, and miR-1207-5p, MALAT1, CERK, TMPRSS13, PCDH17, JARID2

In a study [137], it was hypothesized that the molecular profiling of tumor samples before and after NACT would be helpful in identifying genes likely responsible for drug resistance. Ten tissue samples were taken and sequenced by RNA-seq from eight patients with TNBC who underwent NACT. Three patients did and five patients did not have pCR. SYTL4, a Rab effector in vesicle transport, was considered a leading functional candidate. In particular, SYTL4 in taxane-treated TNBCs was found being a novel chemoresistant gene as validated in TNBC cells, a mouse model and patient-derived organoids. Mechanistically, SYTL4 directly binds microtubules and decreases microtubule stability. In another investigational research [138] a genome-wide CRISPR screening combined with trancriptome analyses, was performed to identify candidates involved in paclitaxel-resistant TNBCs. Cell proliferation, cytotoxicity, immunofluorescent staining, and xenograft assays were carried out to verify the phenotypes of paclitaxel resistance induced by candidate genes, both in vitro and in vivo. MITR, the truncated isoform of histone deacetylase 9 (HDAC9) lacking the deacetylation domain, was enriched in paclitaxel-resistant cells. MITR overexpression resulted in IL11 hyper-expression and activation of downstream JAK/STAT3 signaling. Mechanistically, MITR counteracted MEF2A-induced transcriptional suppression of IL11, ultimately causing paclitaxel resistance. By contrast, pharmacological inhibition of JAK1/2 by ruxolitinib reversed paclitaxel resistance both in vitro and in vivo. Authors concluded that their study elucidated the principal role of MITR/MEF2A/IL11 axis in paclitaxel resistance so appointing a novel therapeutic strategy to improve responses to paclitaxel in TNBC patients. In an experimental study in TNBC cells [139] the role and mechanism of serine protease inhibitor, clade E member 1 (SERPINE1) were evaluated with reference to paclitaxel (PTX) resistance. A bioinformatic analysis of gene expression profiles in PTX resistant cells showed that SERPINE1 was significantly associated with PTX resistance. Accordingly, SERPINE1 mRNA and protein levels were increased in PTX-resistant cells compared with those in PTX-sensitive parent cells. SERPINE1 knockdown significantly inhibited cell survival and promoted cell apoptosis in vitro. In addition, SERPINE1 silencing downregulated the key angiogenetic VEGFA. This study proved the oncogenic role of SERPINE1 in PTX drug resistance of breast cancer and appointed it as a possible target for treating BC. In another study [140], endogenous expression of TNFSF13 in a panel of TNBC cell lines showed strong correlation with PTX and doxorubicin IC50 concentrations. While knocking down TNFSF13 increases PTX efficacy in PTX-insensitive MDA-MB231 cells, recombinant TNFSF13 (recTNFSF13) desensitizes PTX-sensitive HCC1806 cells to PTX. By in-silico analysis and western blotting, TNFSF13 expression was found to inversely correlate with the activity of the Akt-mTOR pathway, which acts as a negative regulator of autophagy activity. Consistent with this finding, the pharmaceutical inhibition of autophagy activity significantly re-establishes the efficacy of PTX in TNFSF13-treated HCC1806 cells. These findings suggest that TNFSF13 promotes chemoresistance in TNBCs through autophagy initiation and that TNFSF13 overexpression accounts for a poor response to CT in TNBCs.

Further studies revealed that the upregulation of miR-5195-3p, miR-18a, and miR1207-5p is a potential predictor of TNBC sensitivity to paclitaxel [141-143].

MALAT1 is a highly conserved lncRNA, and it was found to be a potential biomarker in TNBC, helping to predict clinical outcome and resistance to neoadjuvant paclitaxel and doxorubicin [144].

CERK is a lipid kinase that plays a key role in the level of ceramide and ceramide 1-phosphate (C1P) by phosphorylating ceramide to produce C1P [145]. Ceramide induces apoptosis and is antiproliferative in many tumor cell types; conversely, C1P gives opposite effects [146-148]. It was reported that CERK overexpression strongly affects chemosensitivity and, regarding chemoresistance, can be a biomarker for risk stratification of newly diagnosed TNBC patients. Accordingly, CERK overexpression showed to be a biomarker for chemotherapeutic response in TNBC and higher than two-fold change in CERK (from tumor)/CERK (from normal counterpart) ratio was significantly linked to chemoresistance 
to doxorubicin and paclitaxel $(\mathrm{OR}=2.66,95 \% \mathrm{CI} 1.18-7.34), p=0.04$. CERK overexpression conferred chemoresistance in TNBC cell lines that CERK inhibition allowed to overcome; mechanistic studies suggest that CERK mediates intrinsic resistance and lower response to CT in TNBC by governing several oncogenic pathways such as Ras (rat sarcoma virus)/ERK (extracellular signal-regulated kinase), PI3K/Akt/mTOR, and Ras homolog family member A (RhoA) [149].

The type II transmembrane serine proteases (TTSPs) are a family of cell-surface proteases that play critical roles in different cancers. In a study [150], systematic in silico data analysis, followed by immune-histochemical validation, identified increased expression of the transmembrane protease, serine 13 (TMPRSS13), in invasive ductal carcinoma tissue samples compared to that of normal breast tissue. Targeting TMPRSS13 expression renders aggressive TNBC cell lines highly responsive to paclitaxel and carboplatin. At the molecular level, knockdown of TMPRSS13 in breast cancer cells led to increased protein levels of the tumor-suppressive protease prostasin, which was identified as a potential novel target for TMPRSS13. Regulation of prostasin levels may be a mechanism that contributes to the pro-oncogenic properties of TMPRSS13 in breast cancer.

A study [151] investigated whether PCDH17 gene methylation in TNBC tissues correlated with the effectiveness of NACT. Two-hundred-and-eighty TNBC patients were recruited, and diagnosis was made by core needle biopsy. Overall, 228 patients were positive for PCDH17 methylation, and the 52 remaining were negative. Moreover, 107 patients had pCR after NACT. The pCR rate was $67.3 \%$ among the 52 patients negative for PCDH17 methylation and $31.6 \%$ among the 228 patients positive for PCDH17 methylation. Patients who were negative for PCDH17 methylation and had high Ki67 expression showed significantly higher pCR rates than their counterparts. These findings suggest that PCDH17 methylation status may predict the response to NAC in patients with TNBC. Another study enrolled 14 TNBC patients without pCR following NACT. In seven of them disease progressed within 12 months after mastectomy. Next generation sequencing (NGS) analysis targeting 422 cancer-related genes and in vitro studies was carried out. Among 422 cancer-related genes, alterations in 30 genes were found. TP53 (12/14, 85.7\%) was the most common mutated gene, while $R B 1$ mutations significantly occurred in patients with high Ki-67 scores $(p=0.013)$. Additionally, four mutations of PTPN13 $(57.1 \%, 4 / 7)$ and three of JARID2 $(42.9 \%, 3 / 7)$ were only observed in the short-DFS group, while patients with JARID2 mutation had a significantly shorter DFS period $(p=0.026)$. After knockdown of JARID2 in MD-MBA-231 cells by small interfering RNA (siRNA) the expression of E-cadherin reduced, and the levels of vimentin, MMP7, and MMP9 increased. Authors concluded that JARID2 mutation and high tumor mutational burden (TMB) are potential prognostic and predictive biomarkers in TNBC patients [152].

\subsubsection{Biomarkers Predicting Resistance to Anthracyclines}

Circular RNAs (CircRNAs), miR-449 family, miR-770, a cluster of miRNAs, a cluster of genes, TNFSF13, and plasmacytoma variant translocation 1 (PVT1) factors were described as predictive biomarkers of resistance to anthracyclines.

CircRNAs are strongly involved in the initiation and progression of human cancers. A study [153] investigated mechanisms and the related functions of circUBE2D2 (hsa_circ_0005728) that account for TNBC progression and chemoresistance. The expression of circUBE2D2, miR-512-3p, and cell division cycle associated 3 (CDCA3) mRNA were assessed by qRT-PCR. Silencing of circUBE2D2 decreased doxorubicin resistance of TNBC cells. In-depth mechanism analysis uncovered that circUBE2D2 acted as a miRNA sponge to shield CDCA3 from the attack of miR-512-3p. Moreover, circUBE2D2 depletion induced tumor-suppression, which was importantly impaired upon miR512-3p downregulation or CDCA3 upregulation. Additionally, circUBE2D2 depletion diminished the resistance to doxorubicin through affecting miR-512-3p/CDCA3 axis. miRNA-449 family was found to mediate doxorubicin resistance in TNBC cells by governing cell cycle factors [154]. 
Abnormal expression of miR-770 can inhibit the resistance of TNBC cells to doxorubicin, mainly through regulation of apoptosis and TME [155]. The up/downregulation of an entire cluster of microRNAs, in particular, miR-221/222 and miR-200 families, was found to influence doxorubicin resistance in TNBC [156]. In a study, the effect of doxorubicin in TNBC cell lines was investigated and molecular alterations after a long exposure to doxorubicin were highlighted. In TNBC cell lines, doxorubicin exposure significantly increased the half maximal inhibitory concentration (IC50) values at P12 and P24 compared to that of parenteral cells P0; a total of 196 upregulated and 115 downregulated genes were observed as effects of multiple dose exposure, and 15 overexpressed genes were found to be involved in drug resistance. Also, the presence of some additional mutations in both cell lines was observed. The outcomes of this research may provide novel biomarkers for drug resistance in TNBC. Also, this activity can highlight the potential mechanisms associated with drug resistance, as well as the potential therapies to counteract these mechanisms [157]. In [140], immunohistochemistry findings showed that TNFSF13 protein overexpression occurred in TNBC patients not responding to an anthracycline-based therapy. In a further study [158], plasmacytoma variant translocation 1 (PVT1) increased the resistance of the TNBC cell line MDA-MB-231 to doxorubicin. It was found that PVT1 promoted the protein stability of nuclear factor erythroid 2 like 2 (Nrf2) by inhibiting the binding of kelch-like ECH-associated protein 1 (Keap1) to Nrf2. This induced the resistance of MDA-MB-231 cells to doxorubicin. In another study [159], it was reported that the TRIM37 network affects TNBC tumors allowing tumor cells to resist doxorubicin. Particularly, it was found that TRIM37-directed histone H2A monoubiquitination increased changes in DNA repair that made TP53-mutant TNBC cells resistant to CT. Besides, chemotherapeutic drugs promoted a positive feedback loop via ATM/E2F1 (E2F transcription factor 1)/STAT signaling that boosted the TRIM37 network in chemoresistant cancer cells.

\subsubsection{Biomarkers Predicting Resistance to Gemcitabine and CMF}

Gemcitabine is often used in the treatment of breast cancer and NLRP3 and mir-620 were reported to predict resistance to this drug. In a study conducted in TNBC cells and gemcitabine-resistant cell (GRC) lines [160] the potential mechanism of gemcitabine resistance was investigated. In particular, the sensitivity to different concentrations of gemcitabine with reference to regulation of Nod-like receptor protein 3 (NLRP3) expression was assessed. NLRP3 mRNA expression was determined by RT-PCR and MTT assay evaluated the cell cytotoxicity. NLRP3 overexpression prolonged cell survival and decreased sensitivity to gemcitabine $(p<0.05)$. NLRP3 was highly and more expressed in GRC than in TNBC cells. GRC viability strongly decreased as the gemcitabine concentration increased and NLRP3 overexpression enhanced resistance to gemcitabine in GRC $(p<0.05)$. NLRP3 agonists might induce EMT, promote wnt/beta-catenin signaling and IL-1 $\beta$, while switching off wnt/beta-catenin signaling could result in the inhibition of NLRP3, IL-1 $\beta$ and EMT as well as cell viability in GRC $(p<0.05)$. Overall, this suggests that NLRP3 increases resistance to gemcitabine through IL-1-beta/EMT/Wnt/beta-catenin pathway. miR-620 upregulation in TNBC cells promotes gemcitabine resistance by reducing deoxycytidine monophosphate deaminase (DCTD) expression [161]. NOP10, which is involved in ribosome biogenesis and telomere maintenance, also plays a crucial role in carcinogenesis. In a study [162] NOP10 mRNA levels were investigated using the Molecular Taxonomy of Breast Cancer International Consortium (METABRIC) $(n=1980)$ and Cancer Genome Atlas (TCGA) BC cohorts $(n=854)$. In CT-treated patients (CMF regimen), NOP10 protein overexpression, independent of tumor size and grade and nodal stage, was significantly associated with shorter survival $(p=0.03)$, higher risk of death $(p=0.028)$ and occurrence of distant metastasis $(p=0.02)$. Authors conclude that NOP10 expression can predict CT resistance and that "functional assessments are necessary to decipher the underlying mechanisms and to reveal its potential therapeutic values in various BC subtypes especially in the aggressive TNBC class". 
The main biomarkers predictive of response or chemoresistance and their characteristics are reported in Table 2A,B.

Table 2. Prediction of response or resistance (R) to chemotherapy (CT) in TNBC. B. Prediction of response or R to chemotherapy (CT) in TNBC.

\begin{tabular}{|c|c|c|c|c|c|}
\hline \multicolumn{6}{|c|}{ A. } \\
\hline \multirow{2}{*}{ Predictive Modality } & \multicolumn{2}{|c|}{ Setting } & \multicolumn{2}{|c|}{ Objective } & \multirow{2}{*}{ References } \\
\hline & CS, ES & Kind & Outcome & Drug & \\
\hline \multicolumn{6}{|c|}{ Histologic/Molecular subtype } \\
\hline Metaplastic & \multirow{2}{*}{ CS } & \multirow{2}{*}{ Neoadjuvant } & \multirow{2}{*}{ Low pCR } & $\begin{array}{l}\text { Anthracycline/taxane- } \\
\text { based NACT with or } \\
\text { without carboplatin }\end{array}$ & [100] \\
\hline LAR and MES & & & & $\begin{array}{c}\text { Carboplatin plus } \\
\text { docetaxel }\end{array}$ & [104] \\
\hline \multirow[t]{2}{*}{ BL1 and BL2 } & ES & NA & High proliferation & Cisplatin & [102] \\
\hline & \multicolumn{4}{|c|}{ TILs } & \\
\hline Whole TILs & \multirow{8}{*}{ CS } & \multirow{8}{*}{ Neoadjuvant } & \multirow{8}{*}{$\begin{array}{l}\text { High } \mathrm{pCR} \text { (positive } \\
\text { correlation) }\end{array}$} & \multirow{8}{*}{$\begin{array}{c}\text { Anthracycline/taxane- } \\
\text { based } \\
\text { NACT }\end{array}$} & [107-110] \\
\hline TILs, PD-L1, CD73 (TNP) & & & & & [111] \\
\hline CD3+ cells & & & & & [112] \\
\hline CD4+, CD8+, FOXP3+ cells & & & & & [113] \\
\hline CD20+ cells & & & & & {$[105,107]$} \\
\hline NK cells & & & & & {$[114,115]$} \\
\hline Blood PMN neutrophils & & & & & [119] \\
\hline Blood DCs & & & & & [119] \\
\hline \multicolumn{6}{|c|}{ Biomarkers } \\
\hline HE LncDLX6-AS1 & \multirow{2}{*}{ ES } & \multirow{2}{*}{ NA } & \multirow{2}{*}{$\mathrm{R}$} & \multirow{2}{*}{ Cisplatin } & [121] \\
\hline HE miR-105 and miR-93-3p & & & & & [122] \\
\hline $\begin{array}{l}321 \text { miRNAs (including } \\
\text { miR-34a) expression change }\end{array}$ & \multirow{3}{*}{ CS } & \multirow{3}{*}{ Neoadjuvant } & \multirow{3}{*}{ High pCR } & Carboplatin/paclitaxel & [125] \\
\hline High HRD score & & & & $\begin{array}{l}\text { Anthracycline and/or } \\
\text { taxane-based NACT }\end{array}$ & [129] \\
\hline HRD & & & & $\begin{array}{c}\text { Platinum-containing } \\
\text { NACT }\end{array}$ & {$[131,132]$} \\
\hline Low BRCA1-like score & ES & NA & $\mathrm{R}$ & Cisplatin, docetaxel & [133] \\
\hline BRCAness & CS & Neoadjuvant & Low pCR & Taxane-based NACT & [134] \\
\hline $\begin{array}{c}\text { IL-6, CXCL8, VEGFA, EGR1, } \\
\text { PTGS2, TRIB1 signature }\end{array}$ & ES & NA & $\mathrm{R}$ & Paclitaxel & [135] \\
\hline LE CXCL8-CXCR1/2 axis & CS & Neoadjuvant & High pCR & $\begin{array}{l}\text { Carboplatin plus } \\
\text { paclitaxel }\end{array}$ & [136] \\
\hline
\end{tabular}


Table 2. Cont.

\begin{tabular}{|c|c|c|c|c|c|}
\hline \multicolumn{6}{|c|}{ B. } \\
\hline \multirow{2}{*}{ Predictive Modality } & \multicolumn{2}{|r|}{ Setting } & \multicolumn{2}{|c|}{ Objective } & \multirow{2}{*}{ References } \\
\hline & CS, ES & Kind & Outcome & Drug & \\
\hline \multicolumn{6}{|c|}{ Biomarkers } \\
\hline HE SYTL4 & CS/ES & Neoadjuvant/NA & \multirow{11}{*}{$\mathrm{R}$} & \multirow{3}{*}{ Paclitaxel } & [137] \\
\hline HE MITR & \multirow{4}{*}{ ES } & \multirow{4}{*}{ NA } & & & [138] \\
\hline HE SERPINE1 & & & & & [139] \\
\hline HE TNFS13 & & & & Paclitaxel, anthracycline & [140] \\
\hline LE miR-5195-3p & & & & Paclitaxel & [141] \\
\hline HE miR-18a & CS & Neoadjuvant & & $\begin{array}{l}\text { Paclitaxel-containing } \\
\text { NACT }\end{array}$ & [142] \\
\hline HE miR-1207-5p & ES & NA & & Paclitaxel & [143] \\
\hline HE Long nc RNA MALAT-1 & CS & Neoadjuvant & & \multirow{2}{*}{ Paclitaxel/doxorubicin } & [144] \\
\hline HE CERK & CS/ES & Metastatic/NA & & & [149] \\
\hline HE TMPRSS13 & ES & NA & & Paclitaxel/carboplatin & {$[150]$} \\
\hline High PCDH17 methylation & \multirow[b]{2}{*}{ CS } & \multirow[b]{2}{*}{ Neoadjuvant } & & \multirow{2}{*}{$\begin{array}{c}\text { Taxane/ } \\
\text { anthracycline-based } \\
\text { NACT }\end{array}$} & [151] \\
\hline JARID2 mutation & & & $\begin{array}{c}\text { Short DFS in } \\
\text { patients without } \\
\text { pCR }\end{array}$ & & [152] \\
\hline $\begin{array}{c}\text { circUBE2D2/miR-512- } \\
\text { 3p/CDCA3 } \\
\text { axis }\end{array}$ & ES & NA & $\mathrm{R}$ & \multirow{7}{*}{ Doxorubicin } & [153] \\
\hline HE miRNA-449 family & CS & Neoadjuvant & \multirow{2}{*}{$S$} & & [154] \\
\hline HE miR-770 & ES & NA & & & [155] \\
\hline $\begin{array}{l}\text { LE miR221/222 and miR200 } \\
\text { family }\end{array}$ & CS & ND & \multirow{6}{*}{$\mathrm{R}$} & & [156] \\
\hline $\begin{array}{c}\text { A cluster of } 15 \\
\text { overexpressed genes }\end{array}$ & \multirow{5}{*}{ ES } & \multirow{5}{*}{ NA } & & & [157] \\
\hline HE PVT1 & & & & & [158] \\
\hline HE TRIM37 network & & & & & [159] \\
\hline HE NLRP3 & & & & \multirow{2}{*}{ Gemcitabine } & [160] \\
\hline HE mir-620 & & & & & [161] \\
\hline NOP10 & CS & Adjuvant & Short OS & CMF-treated & [162] \\
\hline
\end{tabular}

CS: clinical setting; ES: experimental setting; NA: not applicable; HE: high expression; R: resistance; LE: low expression; ND: not defined; S: sensitivity.

\section{Drugs Currently Recommended or Helpful in Chemoresistant TNBC}

Recently, based on specific biomarkers, some therapies were tailored to TNBC subsets and became available in clinical practice: olaparib and talazoparib for BRCA1/2 germline mutations carriers; larotrectinib and entrectinib for NTRK gene fusion carriers; anti-trophoblast cell surface antigen 2 (Trop2) antibody drug conjugate therapy. Other targeted therapies are under investigation [163].

5.1. Polymerase ADP-Ribose Inhibitors (PARPi) Are Recommended in TNBC BRCA1/2 Germline Mutation Carriers

About $10-20 \%$ of TNBC has $B R C A 1 / 2$ germline ( $\mathrm{g} B R C A$ ) mutation. In the POSH study, no significant difference in $O S$ was found in positive versus negative gBRCA carriers. De- 
spite this, when the primary analysis in patients with TNBC excluding 37 (7\%) patients who developed a new primary breast or ovarian cancer was repeated, OS at 10 years was $78 \%$ (95\% CI 69-85) in BRCA-positive versus 69\% (64-74; HR 1.24 [95\% CI 0.39-3.96], $p=0.73$ in BRCA-negative patients [164]. Better response to conventional CT depending on HRD deficiency or better immune response might explain the prolonged OS in $\mathrm{gBRCA}$ TNBC. Particularly, in the former instance the activity of DNA-damaging agents such as platinum salts and PARPi should be increased by gBRCA 1/2 mutations. In two Phase III trials carried out in metastatic setting, significantly increased PFS by PARPi as monotherapy compared with standard CT occurred in patients with $\mathrm{gBRCA1/2}$ mutated breast cancer $[165,166]$. Currently, olaparib is recommended in adjuvant and metastatic settings, while talazoparib is recommended in metastatic setting alone of $\mathrm{g} B R C A$ carriers [12,13]. In the Phase II PETREMAC trial, patients with primary TNBC more than $20 \mathrm{~mm}$ received neoadjuvant olaparib for up to 10 weeks before CT. Eighteen out of thirty-two patients showed an objective response (OR) to olaparib (56.3\%). Sixteen out of eighteen responders compared to 4/14 nonresponders, had homologous recombination (HR) mutations and/or BRCA1 methylation [167]. In a study, 107 patients with untreated primary HER2-negative and TNBC with HRD were randomized either to paclitaxel plus olaparib for 12 weeks or paclitaxel plus carboplatinum for 12 weeks, both followed by epirubicin/cyclophosphamide (EC). The pCR rate with paclitaxel-olaparib was $55.1 \%$ versus paclitaxel-carboplatin $48.6 \%$ [168]. In another neoadjuvant study, 20 patients with HER2 negative, gBRCA-positive disease received six months of once per day oral talazoparib, followed by definitive surgery; fifteen patients had TNBC; pCR rate was 53\% [169]. PARPi are under evaluation in combination with CT in neoadjuvant setting (NCT03740893, NCT03150576, NCT02789332), or in combination with chemo and/or immunotherapy in advanced TNBC (NCT03801369, NCT02484404, NCT04690855).

\subsection{Larotrectinib and Entrectinib for NTRK Gene Fusion Carriers}

About $1 \%$ of all solid tumors show somatic chromosomal rearrangements involving the neurotrophic tropomyosin receptor kinase (NTRK1, NTRK2, and NTRK3) genes [170]. Tumor growth promotion derives from TRK gene fusion through overexpression of the proteins and their constitutive downstream activation. The efficacy of larotrectinib, a tropomysin receptor kinase inhibitor, was assessed in the LOXO-101 trial, which showed $71 \%$ OR rate and led to FDA approval $[170,171]$. Entrectinib, another tropomysin receptor kinase inhibitor that proved to be efficacious for patients with NTRK-fusion-positive solid tumors [172], was successively approved by the FDA. NTRK fusions occur, more similarly than in other types, in less than $1 \%$ breast cancers. Ross et al., using comprehensive genomic profiling, identified only 16 tumors $(0.13 \%)$ with NTRK gene fusions among 12,214 locally aggressive, relapsed, or metastatic breast cancers. Among them, nine cases were ductal carcinomas, and three were secretory carcinomas. All tumors were HER2-negative, more often TNBC, and the majority had NTRK1 fusions [173]. Interestingly, human secretory breast carcinoma is less than $0.02 \%$ of all breast cancers [174], and very often (above $90 \%$ ) harbor ETS variant transcription factor 6 (ETV6)-NTRK3 gene fusion previously cloned in pediatric mesenchymal cancers [175]. Most secretory breast carcinoma are classified by genomic profiling as basal-like tumors with triple-negative receptor status [176,177]. However, ETV6-NTRK3 gene fusion is often associated with indolent, slow-growing tumors. This highlights the molecular heterogeneity of TNBCs [178]. To date, in 15 patients with metastatic breast cancer treated with these tropomysin receptor kinase inhibitors, response rates of approximately $80 \%$ were reported $[171,172,179]$. Metastatic breast cancer harboring NTRK fusions and progressing despite previous treatment is approved for receiving TRK inhibitors $[12,13]$.

\subsection{Anti-Trop2 Antibody Drug Conjugate Therapy}

Trop-2 is a glycoprotein overexpressed in multiple epithelial cancers that accounts for pro-growth signaling [180]. Sacituzumab govitecan-hziy is an anti-Trop-2 antibody 
conjugated to an active metabolite of irinotecan (SN-38) [181,182]. This drug inhibits topoisomerase activity and its DNA binding, impedes ligation of cleaved DNA strands and gives rise to double-strand DNA breaks, induces cell death, and blocks DNA replication in tumor cells [180,181]. In heavily pretreated mTNBC patients [182-184], sacituzumab govitecan-hziy improved response rate and median PFS compared to that of standard CT (33.3\% and 5.5 months vs. $10-15 \%$ and $2-3$ months respectively) [184]. The phase 3 ASCENT trial (NCT02574455), a randomized study carried out in the same type of patients to validate the safety and efficacy data [185] was stopped due to the evidence of drug efficacy. The mTNBC patients receiving sacituzumab govitecan-hziy had a PFS of 5.6 months (95\% CI, 4.3-6.3), compared to 1.7 months for patients who received CTs of physician's choice $(p<0.0001)$ [184]. In 2020, Sacituzumab govitecan-hziy received accelerated FDA approval for heavily pretreated and advanced mTNBC.

\subsection{Other Emerging Targeted Therapies}

5.4.1. Targeting Pathological TGF-Beta, Notch, Wnt/Beta-Catenin, Hedgehog, NF-kB, the PI3K-AKT-mTOR, and STAT3/JAK Molecular Pathways

CT-induced TGF- $\beta$ signaling enhances tumor recurrence through IL-8-dependent expansion of CSCs and TGF- $\beta$ pathway inhibitors prevent the development of drugresistant CSCs. Thus, a combination of TGF- $\beta$ inhibitors and anticancer CT could be useful in patients with TNBC [24]. An ongoing Phase I clinical trial is investigating galunisertib, a potent inhibitor of TGF beta type I receptor, in combination with CT in metastatic TNBC (NCT02672475).

In breast cancer cell lines, doxorubicin induced Notch-1 signaling which led to increased ABCC1 expression. Gamma-secretase inhibitor (GSI) inhibited the Notch-1 upregulation of $A B C C 1$, thus rendering the cells more susceptible to doxorubicin [71]. This effect was confirmed in TNBC cells, where GSI enhanced the efficacy of doxorubicin [63]; GSIs-CT combination to treat advanced breast cancer, including TNBC, was investigated in two phase I clinical trials. PF-03084014 GSI, combined with docetaxel, was well tolerated and showed clinical benefit in patients with advanced TNBC [186]. In a recent preclinical study conducted in TNBC patient-derived xenografts with abnormal Notch signaling, a novel GSI, AL101, showed important antitumor effects [185].

Wnt/beta-catenin inhibitors, such as SRI33576, SRI35889, and salinomycin, can inhibit breast CSC proliferation, invasion, and self-renewal in addition to induce apoptosis $[187,188]$. CWP232228, which inhibits Wnt pathway signaling by blocking nuclear beta-catenin interaction with T-cell factor, decreased tumor growth in TNBC xenograft models and was strongly efficacious against chemoresistant breast CSC both in vitro and in vivo [54]. A repurposed drug, clofazimine, decreased the proliferation of TNBC cells and tumor growth in xenograft models. Moreover, clofazimine showed a relevant synergistic effect with doxorubicin with a good tolerability [189]. A recombinant human Frizzled-7 protein antagonist (rhFzd7) decreased proliferation, invasion, and angiogenesis by inhibiting Wnt/beta-catenin pathway, while sensitizing TNBC cells to docetaxel both in vivo and in vitro [190]. LGK974, a small molecule blocking Wnt ligand secretion, is under evaluation in patients with Wnt-ligand dependent malignancies, including TNBC (NCT01351103). Similarly, PTK7-ADC, an antibody-drug conjugate targeting a component of the Wnt/beta pathway, is currently assessed as a therapeutic combination in metastatic TNBC (NCT03243331).

The majority of Hh signaling pathway inhibitors are directed against SMO. However, their efficacy in breast cancer, including TNBC, was disappointing. SMO independent activation of the Hh pathway was demonstrated in TNBC and could partially account for the lack of efficacy of SMO inhibitors [191]. Preclinical data indicate that the use of GLI inhibitors might be preferred for TNBC treatment. GANT61, a direct GLI inhibitor, promoted apoptosis, decreased proliferation, and CSC population in TNBC cell lines [192,193]. However, so far, none of the GLI inhibitors were entered into clinical trials. 
Most NF-kB inhibitors are nonspecific as they affect many other targets besides the NF-kB pathway. This and the pleiotropic effects of NF-B likely account for their high toxicity [194]. Plumbagin, a nonspecific inhibitor, and genistein, a major soy isoflavone inhibiting NF-kB activity via Notch-1 pathway, exert anti-growth and pro-apoptotic effects in TNBC cells [195,196]. Dehydroxymethylepoxyquinomicin (DHMEQ), which inhibits nuclear translocation of NF-B, decreased growth and induced apoptosis in TNBC cells, likely by reducing the activation of this pathway [197].

Targeting the PI3K-AKT-mTOR pathway together with CT can be a useful strategy in aggressive TNBCs with PTEN loss. Everolimus, an mTOR inhibitor, was effective against TNBC in preclinical investigations. Promising results were also obtained for NVPBEZ235, a PI3K/mTOR inhibitor, in TNBC cell lines [102] and several Phase I and II clinical trials investigating the effects of $\mathrm{mTOR}$ and PI3KA inhibitors, alone or in combination with CT, mainly in advanced TNBC are underway (NCT02531932, NCT01931163, NCT01629615, NCT04216472). Recently, AKT proved an important therapeutic target in advanced/metastatic TNBC. A combination of the AKT inhibitor ipatasertib with paclitaxel prolonged PFS and OS of TNBC patients compared to paclitaxel alone. A greater benefit occurred in patients with alterations in the molecular PIK3CA/AKT1/PTEN pathway thus highlighting the relevance of careful patient selection [198]. Accordingly, an ongoing trial is investigating ipatasertib in advanced TNBCs preselected for PIK3CA/AKT1/PTEN alterations (NCT03337724). Uprosertib, another AKT inhibitor, is under evaluation in a Phase II clinical trial on metastatic TNBC (NCT01964924). AZD5363, a novel AKT inhibitor evaluated combined with CT in metastatic TNBC, prolonged OS in a Phase II trial [199].

Promising preclinical results targeting STAT3 and JAK2 in solid tumors including breast cancer were followed by a few clinical studies [200]. For example, JAK1/2 inhibitor ruxolitinib in combination with NACT and AZD9150, a novel antisense nucleotide inhibitor of STAT3, together with durvalumab and paclitaxel are under investigation in triplenegative inflammatory breast cancer (NCT02876302) and in a Phase I/II clinical trial in metastatic TNBC (NCT03742102), respectively.

\subsubsection{Targeting Apoptosis, miRNAs, EGFR, and AR}

Many studies among anticancer strategies focused on Bcl2 family members, TRAIL receptors, and inhibitors of apoptosis (IAPs) [201]. A recent phase II clinical study conducted in metastatic TNBC and investigating tigatuzumab combined with CT was unsuccessful [202]. MEDI3039, a novel death receptor (DR) multivalent agonist, showed elevated antitumoral efficacy both in-vitro and in-murine models of TNBC [203]. Following proapoptotic stimuli, mitochondria release the second mitochondria-derived activator of caspases (SMAC) which acts as an antagonist of IAPs. Thus, SMAC mimetics were constructed as proapoptotic, anticancer agents that could be particularly effective in TNBC [204]. For example, Debio 1143 (AT406) with good preclinical results is under investigation in several Phase I trials on advanced solid tumors, including TNBC (NCT01078649, NCT01930292). In preclinical studies, another SMAC mimetic, LCL161 promoted apoptosis and showed synergistic effects with paclitaxel. Particularly, in a phase II clinical trial, LCL161 administered as a neoadjuvant agent in association with paclitaxel was highly effective; in fact, in localized TNBC, LCL161/paclitaxel combination more than doubled the pCR rate compared with that of paclitaxel alone, although with increased toxicity. However, the pCR effect was only present in the TNBC group preselected for the tumor necrosis factor (TNF) gene expression profile [205].

Regarding therapeutic involvement of miRNAs, two basic strategies were developed: oncogenic miRNAs inhibition and the use of substitutes for rehabilitation of tumor suppressor miRNAs function [206]. Anti-miRNA oligonucleotides, miRNA sponges, small RNA zipper molecules, antagomiRNAs, locked nucleic acid anti-miRNAs, and small molecule inhibitors are the agents commonly used to inhibit oncogenic miRNAs. Antisense-miRNAs and restoration of tumor suppressor miRNAs using miR-mimics inhibited TNBC growth, migration, and invasion in cell lines and xenograft models [207,208]. MiRNAs-based ther- 
apeutic approach seems promising, although further improvements in delivery systems, toxicity, selectivity, and specificity are needed.

EGFR activation/amplification was detected in approximately $25-50 \%$ of TNBC [209,210], and therefore EGFR inhibition should be effective in the treatment of EGFR-driven TNBC. In TNBC, mAbs specific for the receptor and the use of tyrosine kinase inhibitors (TKIs) are two common strategies used for targeting EGFR (and other receptor tyrosine kinases). Cetuximab, an anti-EGFR mAb evaluated in metastatic TNBC in association with cisplatin, moderately increased PFS and OS [211]. However, a Phase II study of cetuximab in combination with carboplatin in metastatic TNBC obtained disappointing results [212]. Panitumumab, another EGFR mAb, showed different efficacy in clinical trials [213,214] and clinical trials of panitumumab in combination with CT in inflammatory TNBC are ongoing (NCT02876107, NCT01036087). Among TKIs, promising findings were reported for apatinib in TNBC [86,215-217]. A clinical trial investigating icotinib in metastatic TNBC is currently recruiting patients (NCT02362230), while the association of anti-EGFR mAbs and TKIs could result in a stronger antitumor action likely due to a synergistic effect [218]. However, in TNBC, although it is a tumor characterized by relatively high rate of EGFR overexpression EGFR, targeted therapy has poor performance. The "EGFR paradox" could explain this phenomenon. According to this hypothesis, EGFR signaling changes during tumor progression, and while EGFR is overexpressed in primary tumors, metastatic cells become intrinsically resistant to EGFR targeted therapy. Accordingly, the two clinical studies of panitumumab that reported the greatest benefit were conducted on operable, primary TNBC $[213,219]$.

Findings from clinical and preclinical studies suggest that LAR is a resistant subtype [104]. LAR tumors are relatively quiescent, which at least in part could explain their CT resistance [106]. Bicalutamide, a first-generation AR antagonist, induces cell apoptosis and inhibits cell motility and invasiveness in cell line MDA-MB-453 [220] and cell lines representing the LAR subtype are sensitive to AR antagonist bicalutamide and 17-DMAG [102]. In a first phase II study of metastatic AR-positive TNBC breast cancer patients treated with bicalutamide, a six-month clinical benefit rate of $19 \%$ and a median PFS of 12 weeks occurred [221]. In another Phase II single-arm trial conducted in 146 AR-positive TNBC patients with inoperable locally advanced or metastatic diseases whose tumors had $\geq 10 \%$ AR expression, a different AR inhibitor, abiraterone acetate plus prednisone, showed comparable results to bicalutamide [222]. Enzalutamide, a second-generation AR antagonist, showed clinical activity in a Phase II study recruiting patients with locally advanced or metastatic AR-positive TNBC [223]. Moreover, AR inhibition with enzalutamide was an inductor of radiation sensitivity in AR-positive TNBC cell lines, proposing AR inhibition as a radio-sensitization strategy [224]. The START trial (NCT03383679) is an ongoing randomized Phase II study testing the efficacy of darolutamide, a new AR antagonist, compared to capecitabine for AR-positive, locally recurrent, or metastatic TNBC.

Drugs currently recommended or potentially helpful in chemoresistant TNBC are reported in Table $3 \mathrm{~A}-\mathrm{C}$. 
Table 3. Drugs currently recommended or potentially helpful in chemoresistant TNBC.

\begin{tabular}{|c|c|c|c|c|}
\hline \multicolumn{5}{|c|}{ A. } \\
\hline Drug & $\begin{array}{c}\text { Target/Mechanism of } \\
\text { Action }\end{array}$ & CS/ES & Outcome & $\begin{array}{c}\text { Reference/NCT } \\
\text { Number }\end{array}$ \\
\hline \multicolumn{5}{|c|}{ Currently recommended } \\
\hline Olaparib & \multirow{2}{*}{ PARP inhibitor } & $\begin{array}{c}\text { Metastatic, in HER2 } \\
\text { negative BC pts with a } \\
\text { germline } B R C A \text { mutation } \\
(C S)\end{array}$ & \multirow{2}{*}{ Higher objective RR and PFS } & [165] \\
\hline Talazoparib & & $\begin{array}{l}\text { Advanced, in } B C \text { pts with } \\
\text { germline } B R C A \text { mutation } \\
\text { (CS) }\end{array}$ & & [166] \\
\hline Larotrectinib & \multirow{2}{*}{$\begin{array}{l}\text { Inhibitor of } \\
\text { tropomyosin receptor } \\
\text { kinase (TRK) }\end{array}$} & \multirow{2}{*}{$\begin{array}{l}\text { Advanced, in NTRK gene } \\
\text { fusion-positive solid } \\
\text { tumours (CS) }\end{array}$} & ORR $71 \%$ & [170] \\
\hline Entrectinib & & & $\begin{array}{l}\text { ORR } 57 \% \text {; Median duration } \\
\text { of response } 10 \text { months }\end{array}$ & [172] \\
\hline $\begin{array}{l}\text { Sacituzumab } \\
\text { govitecan }\end{array}$ & $\begin{array}{l}\text { Anti-Trop2 antibody } \\
\text { drug conjugate }\end{array}$ & $\begin{array}{l}\text { Metastatic, in heavily } \\
\text { pretreated pts (CS) }\end{array}$ & $\begin{array}{l}\text { RR } 33.3 \% \text {; median duration } \\
\text { of response } 7.7 \text { months; } \\
\text { clinical benefit rate } 45.4 \% \text {; } \\
\text { median PFS } 5.5 \text { months; OS } \\
13.0 \text { months }\end{array}$ & [184] \\
\hline \multicolumn{5}{|c|}{ Under investigation } \\
\hline Galunisertib & $\begin{array}{l}\text { TGF beta type I } \\
\text { receptor inhibitor }\end{array}$ & $\begin{array}{c}\text { Metastatic, in combination } \\
\text { with CT (CS) }\end{array}$ & NA & $\begin{array}{l}\text { NCT02672475 } \\
\quad(\text { phase I) }\end{array}$ \\
\hline PF-03084014 & \multirow{2}{*}{$\begin{array}{l}\text { Gamma secretase } \\
\text { inhibitor }\end{array}$} & $\begin{array}{l}\text { Advanced, in combination } \\
\text { with docetaxel (CS) }\end{array}$ & Median PFS 4.1 months & {$[186]$} \\
\hline AL101 & & $\begin{array}{c}\text { Patient-derived xenografts } \\
\text { with abnormal Notch } \\
\text { signaling (ES) }\end{array}$ & Inhibition of tumor growth & [185] \\
\hline SRI33576, SRI35889 & \multirow{7}{*}{$\begin{array}{l}\text { wnt/beta-catenin } \\
\text { inhibitors }\end{array}$} & Cell lines (ES) & $\begin{array}{l}\text { Pro-apoptotic effects by } \\
\text { downregulating LRP6 }\end{array}$ & [187] \\
\hline Salinomycin & & Breast CSCs (ES) & $\begin{array}{l}\text { inhibition of proliferation, } \\
\text { invasion, and self-renewal } \\
\text { while inducing apoptosis }\end{array}$ & {$[185,186]$} \\
\hline CWP232228 & & Xenograft models (ES) & Inhibition of tumor growth & {$[54]$} \\
\hline Clofazimine & & $\begin{array}{l}\text { Cells and xenograft models } \\
\text { (ES) }\end{array}$ & inhibition of proliferation; & [189] \\
\hline $\begin{array}{l}\text { Frizzled-7 protein } \\
\text { antagonist (rhFzd7) }\end{array}$ & & Cells and xenografts (ES) & $\begin{array}{l}\text { Inhibition of proliferation, } \\
\text { invasion, and angiogenesis } \\
\text { while sensitizing cells to } \\
\text { docetaxel }\end{array}$ & [190] \\
\hline LGK974 & & $\begin{array}{c}\text { Advanced, in pts with } \\
\text { wnt-ligand dependent } \\
\text { malignancies, including } \\
\text { TNBC (CS) }\end{array}$ & \multirow{2}{*}{ NA } & $\begin{array}{l}\text { NCT01351103 } \\
\quad(\text { phase I) }\end{array}$ \\
\hline PTK7-ADC & & $\begin{array}{c}\text { Metastatic, in combination } \\
\text { with gedatolisib (dual } \\
\text { PI3K-mTORC1/2 inhibitor) } \\
\text { (CS) }\end{array}$ & & $\begin{array}{l}\text { NCT03243331 } \\
\quad(\text { phase I) }\end{array}$ \\
\hline
\end{tabular}


Table 3. Cont.

\begin{tabular}{|c|c|c|c|c|}
\hline & & B. & & \\
\hline Drug & $\begin{array}{c}\text { Target/Mechanism of } \\
\text { Action }\end{array}$ & CS/ES & Outcome & $\begin{array}{c}\text { Reference/NCT } \\
\text { Number }\end{array}$ \\
\hline \multicolumn{5}{|c|}{ Under investigation } \\
\hline GANT61 & $\begin{array}{l}\text { Hh/direct GLI } \\
\text { inhibitor }\end{array}$ & \multirow{4}{*}{ Cell lines (ES) } & $\begin{array}{l}\text { promoted apoptosis, reduced } \\
\text { proliferation, and decreased } \\
\text { CSC population }\end{array}$ & {$[192,193]$} \\
\hline Plumbagin & $\begin{array}{l}\text { Non-specific NF-kB } \\
\text { inhibitor }\end{array}$ & & $\begin{array}{c}\text { Decreased cell viability and } \\
\text { promoted apoptosis }\end{array}$ & [195] \\
\hline Genistein & NF-kB inhibitor & & $\begin{array}{c}\text { Anti-growth and } \\
\text { pro-apoptotic effects }\end{array}$ & [196] \\
\hline DHMEQ & $\begin{array}{c}\text { Nuclear translocation } \\
\text { of NF-B inhibitor }\end{array}$ & & $\begin{array}{l}\text { Decreased growth and } \\
\text { induction of apoptosis }\end{array}$ & [197] \\
\hline \multirow{2}{*}{ Everolimus } & \multirow{2}{*}{ mTOR inhibitor } & $\begin{array}{l}\text { Advanced, in combination } \\
\text { with carboplatin (CS) }\end{array}$ & \multirow{4}{*}{ NA } & $\begin{array}{l}\text { NCT02531932 } \\
\text { (phase II) }\end{array}$ \\
\hline & & $\begin{array}{l}\text { Advanced, in combination } \\
\text { with cisplatin (CS) }\end{array}$ & & $\begin{array}{l}\text { NCT01931163 } \\
\quad \text { (phase II) }\end{array}$ \\
\hline BKM120 & \multirow[b]{2}{*}{ PI3K inhibitor } & Metastatic (CS) & & $\begin{array}{l}\text { NCT01629615 } \\
\text { (phase II) }\end{array}$ \\
\hline Alpelisib & & $\begin{array}{l}\text { Neoadjuvant, in } \\
\text { combination with } \\
\text { nab-paclitaxel in } \\
\text { anthracycline refractory pts } \\
\text { with PIK3CA or PTEN } \\
\text { alterations (CS) }\end{array}$ & & $\begin{array}{l}\text { NCT04216472 } \\
\quad(\text { phase I) }\end{array}$ \\
\hline Ipatasertib & \multirow{4}{*}{ AKT inhibitor } & $\begin{array}{c}\text { Locally } \\
\text { advanced/metastatic, first } \\
\text { line (phase II), in } \\
\text { combination with } \\
\text { paclitaxel (CS) }\end{array}$ & Prolonged PFS and OS & [198] \\
\hline Ipatasertib & & $\begin{array}{c}\text { Advanced, in } \\
\text { PIK3CA/AKT1/PTEN- } \\
\text { altered pts, in combination } \\
\text { with paclitaxel versus } \\
\text { placebo + paclitaxel (CS) }\end{array}$ & \multirow[t]{2}{*}{ NA } & $\begin{array}{l}\text { NCT03337724 } \\
\text { (phase III) }\end{array}$ \\
\hline Uprosertib & & $\begin{array}{l}\text { Metastatic, in combination } \\
\text { with trametinib (CS) }\end{array}$ & & $\begin{array}{l}\text { NCT01964924 } \\
\quad \text { (phase II) }\end{array}$ \\
\hline AZD5363 & & $\begin{array}{c}\text { Metastatic, in combination } \\
\text { with CT (CS) }\end{array}$ & Prolonged OS & [201] \\
\hline Ruxolitinib & JAK1/2 inhibitor & $\begin{array}{c}\text { Neoadjuvant, in } \\
\text { combination with CT (CS) }\end{array}$ & NA & $\begin{array}{l}\text { NCT02876302 } \\
\text { (phase II) }\end{array}$ \\
\hline
\end{tabular}


Table 3. Cont.

\begin{tabular}{|c|c|c|c|c|}
\hline \multicolumn{5}{|c|}{ C. } \\
\hline Drug & $\begin{array}{c}\text { Target/Mechanism of } \\
\text { Action }\end{array}$ & CS/ES & Outcome & $\begin{array}{c}\text { Reference/NCT } \\
\text { Number }\end{array}$ \\
\hline \multicolumn{5}{|c|}{ Under investigation } \\
\hline AZD9150 & $\begin{array}{l}\text { Antisense nucleotide } \\
\text { inhibitor of STAT3 }\end{array}$ & $\begin{array}{l}\text { Metastatic, in combination } \\
\text { with durvalumab and } \\
\text { paclitaxel (CS) }\end{array}$ & NA & $\begin{array}{l}\text { NCT03742102 } \\
\text { (phase I/II) }\end{array}$ \\
\hline MEDI3039 & Apoptosis/DR agonist & $\begin{array}{l}\text { In-vitro and in-murine } \\
\text { models (ES) }\end{array}$ & Tumor growth inhibition & [205] \\
\hline Debio 1143 & IAP antagonist & $\begin{array}{l}\text { Advanced, solid tumors } \\
\text { including TNBC (CS) }\end{array}$ & NA & $\begin{array}{l}\text { NCT01078649, } \\
\text { NCT01930292 } \\
\quad \text { (phase I) }\end{array}$ \\
\hline LCL161 & SMAC analog & $\begin{array}{l}\text { Neoadjuvant, in } \\
\text { combination with } \\
\text { paclitaxel (CS) }\end{array}$ & $\begin{array}{l}\text { Doubled pCR rate in a group } \\
\text { preselected for the tumor } \\
\text { necrosis factor (TNF) gene } \\
\text { expression profile }\end{array}$ & [205] \\
\hline $\begin{array}{l}\text { antisense-miRNA-21 } \\
\text { and antisense- } \\
\text { miRNA-10b } \\
\text { co-delivery }\end{array}$ & $\begin{array}{l}\text { Inhibition of oncogenic } \\
\text { miRNAs }\end{array}$ & Murine models (ES) & reduced tumor growth & [207] \\
\hline $\begin{array}{l}\text { miR-mimic } \\
\text { recombinant vectors }\end{array}$ & $\begin{array}{l}\text { Restoration of tumor } \\
\text { suppressor miRNAs }\end{array}$ & Cell line (ES) & $\begin{array}{l}\text { Reduced migration and } \\
\text { invasion }\end{array}$ & [209] \\
\hline Panitumumab & anti-EGFR mAb & $\begin{array}{l}\text { Neoadjuvant, in } \\
\text { combination with CT }\end{array}$ & \multirow[b]{2}{*}{ NA } & $\begin{array}{l}\text { NCT02876107 } \\
\text { (phase II) } \\
\text { NCT01036087 } \\
\text { (phase II) }\end{array}$ \\
\hline Apatinib & \multirow[t]{2}{*}{ Anti-EGFR TKI } & $\begin{array}{l}\text { Advanced, alone or in } \\
\text { combination with CT (CS) }\end{array}$ & & $\begin{array}{c}\text { NCT05019690 } \\
\text { (phase I/II) } \\
\text { NCT03932526 } \\
\text { (phase II) } \\
\text { NCT03254654 } \\
\text { (phase II) }\end{array}$ \\
\hline Icotinib & & Metastatic, pre-treated (CS) & Under evaluation & $\begin{array}{l}\text { NCT02362230 } \\
\text { (phase II) }\end{array}$ \\
\hline Bicalutamide & \multirow{4}{*}{ AR antagonist } & $\begin{array}{l}\text { Metastatic, AR-positive } \\
\text { (CS) }\end{array}$ & $\begin{array}{c}\text { six-month CBR } 19 \% \text {, median } \\
\text { PFS } 12 \text { weeks }\end{array}$ & [221] \\
\hline Abiraterone acetate & & $\begin{array}{l}\text { Advanced or metastatic, } \\
\text { AR-positive pts, in } \\
\text { combination with } \\
\text { prednisone (CS) }\end{array}$ & $\begin{array}{l}\text { six-month CBR } 20.0 \% \text {, ORR } \\
6.7 \% \text {, median PFS } 2.8 \text { months }\end{array}$ & [222] \\
\hline Enzalutamide & & $\begin{array}{c}\text { Locally advanced or } \\
\text { metastatic AR-positive pts } \\
\text { (CS) }\end{array}$ & $\begin{array}{c}16 \text { weeks CBR } 33 \% \text {, median } \\
\text { PFS } 3.3 \text { months, median OS } \\
17.6 \text { months }\end{array}$ & [223] \\
\hline Darolutamide & & $\begin{array}{c}\text { Locally recurrent or } \\
\text { metastatic, in AR-positive } \\
\text { pts (CS) }\end{array}$ & NA & $\begin{array}{l}\text { NCT03383679 } \\
\quad \text { (phase II) }\end{array}$ \\
\hline
\end{tabular}

CT: chemotherapy; CS: clinical setting; ES: experimental setting; NA: not available; PARP: polymerase ADPribose; RR: response rate; PFS: progression free survival; NTRK: neurotrophic tropomyosin receptor kinase; ORR: overall response rate; Trop-2: trophoblast cell-surface antigen; TGF: tumor growth factor; LRP6: lipoprotein receptor-related protein-6; CSCs: cancer stem cells; PI3K: phosphatidyl inositol 3-kinase; mTORC1 /2: mammalian target of rapamycin complex 1/2; GLI: glioma-associated oncogene transcription factor; NFkB: nuclear factor kappa-light-chain-enhancer of activated B cells; mTOR: mammalian target of rapamycin; Akt: protein kinase $\mathrm{B}_{\text {; }}$ PTEN: phosphatase and tensin homolog; JAK1/2: Janus kinase 1/2; STAT: signal transducer and activator of transcription; DR: death receptor; IAP: inhibitor of apoptosis; SMAC: second mitochondria-derived activator of caspases; TKi: tyrosine kinase inhibitor; AR: androgen receptor; pCR: pathological complete response; CBR: clinical benefit rate; OS: overall survival. 


\section{Discussion and Conclusions}

Among breast cancer subtypes, TNBC is associated with the worst prognosis [2,4] and in spite of efforts performed in the last decades, no significant improvement in PFS and OS was obtained $[225,226]$. At present, CT is the mainstay treatment in TNBC; however, resistance to CT frequently occurs. However, TNBC is a heterogeneous disease, and many molecular mechanisms are involved in chemoresistance. Identification of these mechanisms is of particular relevance, as it can help in improving prognosis and therapy. Some biomarkers capable of predict resistance to specific chemotherapeutic agents were identified and are expected to be validated in future studies. These predictive factors could guide the therapeutic approach in both early and advanced disease. Current guidelines recommend NACT in operable TNBC $>2 \mathrm{~cm}$ or for breast conservation or in $\mathrm{cN}+$ disease likely to become $\mathrm{cN0}$; recently, NACT was considered not an option, but rather the preferred treatment strategy for TNBC patients in clinical practice [15]. However, disease progression during NACT is a potential risk [12,13]. Therefore, both in neoadjuvant and advanced settings, a more tailored approach and a more accurate selection of the employed drugs are main aims. Many studies based upon molecular biology defined the use of new drugs that could be essential in identifying the mechanisms accounting for chemoresistance to a specific antiblastic in each patient. Therefore, emerging therapies allow to select specific antiblastics that, alone or by integrating the conventional therapeutic approach, may overcome/hinder chemoresistance.

In particular, PARP inhibitors improved prognosis in metastatic $B R C A$ mutated patients $[165,166]$ and are under evaluation in the neoadjuvant setting; TRK inhibitors showed activity and are approved in rare metastatic breast cancers harboring NTRK fusions and progressing despite previous treatment [171,172]; sacituzumab govitecan, based on the results of the phase III ASCENT trial, showed a PFS of 5.6 months compared to 1.7 months for patients who received chemotherapies of physician's choice, and received accelerated FDA approval for pretreated and advanced metastatic TNBC [184]. However, some criticism arose around the results and the cost/effectiveness ratio of this trial $[227,228]$. $\mathrm{PI} 3 \mathrm{~K} / \mathrm{Akt} / \mathrm{mTOR}$ and EGFR inhibitors as well as antiandrogens showed promising results and are under evaluation in Phase II/III clinical trials. Immunotherapy is another interesting option. However, pembrolizumab or atezolizumab combined with CT increased the median PFS 4.1 and 2.5 months, respectively, and the clinical benefit was modest. Only about $40 \%$ of TNBCs are PD-L1 + and not all PD-L1 + patients with advanced TNBC respond to PD-L1 inhibitors. It is likely that redundant pathways of immune suppression are active in breast cancer or that important pathways of immune activation are silent. Therefore, new strategies targeting multiple pathways of immunoregulation [229] can improve the efficacy of the currently available and other new developed immunotherapies.

Author Contributions: P.F. conceived and planned the article; P.F. and A.N. equally contributed to writing the article; C.S., M.G., I.B. and G.L. assisted with the preparation and revision of the manuscript. All authors have read and agreed to the published version of the manuscript.

Funding: This research received no external funding.

Institutional Review Board Statement: Not applicable.

Informed Consent Statement: Not applicable.

Data Availability Statement: Not applicable.

Conflicts of Interest: The authors declare no conflict of interest.

\section{References}

1. Triple-Negative Breast Cancer. Available online: https://www.cancer.org/cancer/breast-cancer/about/types-of-breast-cancer/ triple-negative.html (accessed on 15 January 2022).

2. Dent, R.; Trudeau, M.; Pritchard, K.I.; Hanna, W.M.; Kahn, H.K.; Sawka, C.A.; Lickley, L.A.; Rawlinson, E.; Sun, P.; Narod, S.A. Triple-negative breast cancer: Clinical features and patterns of recurrence. Clin. Cancer Res. 2007, 13, 4429-4434. [CrossRef] [PubMed] 
3. Carey, L.A. The triple negative paradox: Primary tumor chemosensitivity of breast cancer subtypes. Clin. Cancer Res. 2007, 13, 2329-2334. [CrossRef] [PubMed]

4. Kennecke, H.; Yerushalmi, R.; Woods, R.; Cheang, M.C.; Voduc, D.; Speers, C.H.; Nielsen, T.O.; Gelmon, K. Metastatic behavior of breast cancer subtypes. J. Clin. Oncol. 2010, 28, 3271-3277. [CrossRef] [PubMed]

5. Sørlie, T.; Perou, C.M.; Tibshirani, R.; Aas, T.; Geisler, S.; Johnsen, H.; Hastie, T.; Eisen, M.B.; van de Rijn, M.; Jeffrey, S.S.; et al. Gene expression patterns of breast carcinomas distinguish tumor subclasses with clinical implications. Proc. Natl. Acad. Sci. USA 2001, 98, 10869-10874. [CrossRef] [PubMed]

6. Prat, A.; Adamo, B.; Cheang, M.C.; Anders, C.K.; Carey, L.A.; Perou, C.M. Molecular characterization of basal-like and non-basallike triple-negative breast cancer. Oncologist 2013, 18, 123-133. [CrossRef] [PubMed]

7. Prat, A.; Parker, J.S.; Karginova, O.; Fan, C.; Livasy, C.; Herschkowitz, J.I.; He, X.; Perou, C.M. Phenotypic and molecular characterization of the claudin-low intrinsic subtype of breast cancer. Breast Cancer Res. 2010, 12, R68. [CrossRef] [PubMed]

8. Da Silva, J.L.; Cardoso Nunes, N.C.; Izetti, P.; de Mesquita, G.G.; de Melo, A.C. Triple negative breast cancer, A thorough review of biomarkers. Crit. Rev. Oncol. Hematol. 2020, 145, 102855. [CrossRef]

9. Lehmann, B.D.; Pietenpol, J.A. Clinical implications of molecular heterogeneity in triple negative breast cancer. Breast 2015, 24, S36-S40. [CrossRef]

10. Burstein, M.D.; Tsimelzon, A.; Poage, G.M.; Covington, K.R.; Contreras, A.; Fuqua, S.A.; Savage, M.I.; Osborne, C.K.; Hilsenbeck, S.G.; Chang, J.C.; et al. Comprehensive genomic analysis identifies novel subtypes and targets of triple-negative breast cancer. Clin. Cancer Res. 2015, 21, 1688-1698. [CrossRef]

11. Lebert, J.M.; Lester, R.; Powell, E.; Seal, M.; McCarthy, J. Advances in the systemic treatment of triple-negative breast cancer. Curr. Oncol. 2018, 25, S142-S150. [CrossRef]

12. NCCN Guidelines 2021. Available online: https://www.nccn.org/professionals/physician_gls/pdf/breast.pdf (accessed on 15 January 2022).

13. ESMO Guidelines. Available online: https://www.esmo.org/guidelines/breast-cancer (accessed on 15 January 2022 ).

14. Liedtke, C.; Mazouni, C.; Hess, K.R.; André, F.; Tordai, A.; Mejia, J.A.; Symmans, W.F.; Gonzalez-Angulo, A.M.; Hennessy, B.; Green, M.; et al. Response to neoadjuvant therapy and long-term survival in patients with triple-negative breast cancer. J. Clin. Oncol. 2008, 26, 1275-1281. [CrossRef]

15. Montemurro, F.; Nuzzolese, I.; Ponzone, R. Neoadjuvant or adjuvant chemotherapy in early breast cancer? Expert Opin. Pharmacother. 2020, 21, 1071-1082. [CrossRef]

16. Longley, D.B.; Johnston, P.G. Molecular mechanisms of drug resistance. J. Pathol. 2005, 205, 275-292. [CrossRef] [PubMed]

17. Shibata, M.; Hoque, M.O. Targeting Cancer Stem Cells: A Strategy for Effective Eradication of Cancer. Cancers 2019, 11, 732. [CrossRef] [PubMed]

18. Creighton, C.J.; Li, X.; Landis, M.; Dixon, J.M.; Neumeister, V.M.; Sjolund, A.; Rimm, D.L.; Wong, H.; Rodriguez, A.; Herschkowitz, J.I.; et al. Residual breast cancers after conventional therapy display mesenchymal as well as tumor-initiating features. Proc. Natl. Acad. Sci. USA 2009, 106, 13820-13825. [CrossRef] [PubMed]

19. Lee, H.E.; Kim, J.H.; Kim, Y.J.; Choi, S.Y.; Kim, S.W.; Kang, E.; Chung, I.Y.; Kim, I.A.; Kim, E.J.; Choi, Y.; et al. An increase in cancer stem cell population after primary systemic therapy is a poor prognostic factor in breast cancer. Br. J. Cancer 2011, 104, 1730-1738. [CrossRef] [PubMed]

20. Park, S.Y.; Lee, H.E.; Li, H.; Shipitsin, M.; Gelman, R.; Polyak, K. Heterogeneity for stem cell-related markers according to tumor subtype and histologic stage in breast cancer. Clin. Cancer Res. 2010, 16, 876-887. [CrossRef]

21. Ma, F.; Li, H.; Wang, H.; Shi, X.; Fan, Y.; Ding, X.; Lin, C.; Zhan, Q.; Qian, H.; Xu, B. Enriched CD44(+)/CD24(-) population drives the aggressive phenotypes presented in triple-negative breast cancer (TNBC). Cancer Lett. 2014, 353, 153-159. [CrossRef]

22. Ma, F.; Li, H.; Li, Y.; Ding, X.; Wang, H.; Fan, Y.; Lin, C.; Qian, H.; Xu, B. Aldehyde dehydrogenase 1 (ALDH1) expression is an independent prognostic factor in triple negative breast cancer (TNBC). Medicine 2017, 96, e6561. [CrossRef]

23. Wang, H.; Wang, L.; Song, Y.; Wang, S.; Huang, X.; Xuan, Q.; Kang, X.; Zhang, Q. CD44+/CD24- phenotype predicts a poor prognosis in triple-negative breast cancer. Oncol. Lett. 2017, 14, 5890-5898. [CrossRef]

24. Bhola, N.E.; Balko, J.M.; Dugger, T.C.; Kuba, M.G.; Sánchez, V.; Sanders, M.; Stanford, J.; Cook, R.S.; Arteaga, C.L. TGF- $\beta$ inhibition enhances chemotherapy action against triple-negative breast cancer. J. Clin. Investig. 2013, 123, 1348-1358. [CrossRef] [PubMed]

25. Samanta, D.; Gilkes, D.M.; Chaturvedi, P.; Xiang, L.; Semenza, G.L. Hypoxia-inducible factors are required for chemotherapy resistance of breast cancer stem cells. Proc. Natl. Acad. Sci. USA 2014, 111, E5429-E5438. [CrossRef] [PubMed]

26. Britton, K.M.; Eyre, R.; Harvey, I.J.; Stemke-Hale, K.; Browell, D.; Lennard, T.W.J.; Meeson, A.P. Breast cancer, side population cells and ABCG2 expression. Cancer Lett. 2012, 323, 97-105. [CrossRef] [PubMed]

27. Zhou, S.; Schuetz, J.D.; Bunting, K.D.; Colapietro, A.M.; Sampath, J.; Morris, J.J.; Lagutina, I.; Grosveld, G.C.; Osawa, M.; Nakauchi, H.; et al. The ABC transporter Bcrp1/ABCG2 is expressed in a wide variety of stem cells and is a molecular determinant of the side-population phenotype. Nat. Med. 2001, 7, 1028-1034. [CrossRef]

28. Sissung, T.M.; Baum, C.E.; Kirkland, C.T.; Gao, R.; Gardner, E.R.; Figg, W.D. Pharmacogenetics of membrane transporters: An update on current approaches. Mol. Biotechnol. 2010, 44, 152-167. [CrossRef] 
29. Yamada, A.; Ishikawa, T.; Ota, I.; Kimura, M.; Shimizu, D.; Tanabe, M.; Chishima, T.; Sasaki, T.; Ichikawa, Y.; Morita, S.; et al. High expression of ATP-binding cassette transporter ABCC11 in breast tumors is associated with aggressive subtypes and low disease-free survival. Breast Cancer Res. Treat. 2013, 137, 773-782. [CrossRef]

30. Guestini, F.; Ono, K.; Miyashita, M.; Ishida, T.; Ohuchi, N.; Nakagawa, S.; Hirakawa, H.; Tamaki, K.; Ohi, Y.; Rai, Y.; et al. Impact of Topoisomerase II $\alpha$, PTEN, ABCC1/MRP1, and KI67 on triple-negative breast cancer patients treated with neoadjuvant chemotherapy. Breast Cancer Res. Treat. 2019, 2, 275-288. [CrossRef]

31. Das, S.; Samant, R.S.; Shevde, L.A. Nonclassical activation of Hedgehog signaling enhances multidrug resistance and makes cancer cells refractory to Smoothened-targeting Hedgehog inhibition. J. Biol. Chem. 2013, 288, 11824-11833. [CrossRef]

32. Arumugam, A.; Subramani, R.; Nandy, S.B.; Terreros, D.; Dwivedi, A.K.; Saltzstein, E.; Lakshmanaswamy, R. Silencing growth hormone receptor inhibits estrogen receptor negative breast cancer through ATP-binding cassette sub-family G member 2 . Exp. Mol. Med. 2019, 51, 1-13. [CrossRef]

33. Oguri, T.; Bessho, Y.; Achiwa, H.; Ozas, H.; Maeno, K.; Maeda, H.; Sato, S.; Ueda, R. MRP8/ABCC11 directly confers resistance to 5-fluorouracil. Mol. Cancer Ther. 2007, 6, 122-127. [CrossRef]

34. Vaupel, P. Hypoxia and aggressive tumor phenotype: Implications for therapy and prognosis. Oncologist 2008, 13, 21-26. [CrossRef]

35. Gerweck, L.E.; Vijayappa, S.; Kozin, S. Tumor $\mathrm{pH}$ controls the in vivo efficacy of weak acid and base chemotherapeutics. Mol. Cancer Ther. 2006, 5, 1275-1279. [CrossRef] [PubMed]

36. Cosse, J.P.; Michiels, C. Tumour hypoxia affects the responsiveness of cancer cells to chemotherapy and promotes cancer progression. Anticancer. Agents Med. Chem. 2008, 8, 790-797. [CrossRef] [PubMed]

37. Kim, H.; Lin, Q.; Glazer, P.M.; Yun, Z. The hypoxic tumor microenvironment in vivo selects the cancer stem cell fate of breast cancer cells. Breast Cancer Res. 2018, 20, 16. [CrossRef] [PubMed]

38. Chouaib, S.; Noman, M.Z.; Kosmatopoulos, K.; Curran, M.A. Hypoxic stress: Obstacles and opportunities for innovative immunotherapy of cancer. Oncogene 2017, 36, 439-445. [CrossRef] [PubMed]

39. Xiang, L.; Liu, Z.H.; Huan, Q.; Su, P.; Du, G.J.; Wang, Y.; Gao, P.; Zhou, G.Y. Hypoxia-inducible factor-2a is associated with ABCG2 expression, histology-grade and Ki67 expression in breast invasive ductal carcinoma. Diagn. Pathol. 2012, 7, 32. [CrossRef]

40. Lv, Y.; Zhao, S.; Han, J.; Zheng, L.; Yang, Z.; Zhao, L. Hypoxia-inducible factor-1 $\alpha$ induces multidrug resistance protein in colon cancer. Onco Targets Ther. 2015, 8, 1941-1948. [CrossRef]

41. Daskalaki, I.; Gkikas, I.; Tavernarakis, N. Hypoxia and Selective Autophagy in Cancer Development and Therapy. Front. Cell Dev. Biol. 2018, 6, 104. [CrossRef]

42. Livasy, C.A.; Karaca, G.; Nanda, R.; Tretiakova, M.S.; Olopade, O.I.; Moore, D.T.; Perou, C.M. Phenotypic evaluation of the basal-like subtype of invasive breast carcinoma. Mod. Pathol. 2006, 19, 264-271. [CrossRef]

43. Tan, E.Y.; Yan, M.; Campo, L.; Han, C.; Takano, E.; Turley, H.; Candiloro, I.; Pezzella, F.; Gatter, K.C.; Millar, E.K.; et al. The key hypoxia regulated gene CAIX is upregulated in basal-like breast tumours and is associated with resistance to chemotherapy. Br. J. Cancer 2009, 100, 405-411. [CrossRef]

44. Simões-Wüst, A.P.; Schürpf, T.; Hall, J.; Stahel, R.A.; Zangemeister-Wittke, U. Bcl-2/bcl-xL bispecific antisense treatment sensitizes breast carcinoma cells to doxorubicin, paclitaxel and cyclophosphamide. Breast Cancer Res. Treat. 2002, 76, 157-166. [CrossRef] [PubMed]

45. Campbell, K.J.; Dhayade, S.; Ferrari, N.; Sims, A.H.; Johnson, E.; Mason, S.M.; Dickson, A.; Ryan, K.M.; Kalna, G.; Edwards, J.; et al. MCL-1 is a prognostic indicator and drug target in breast cancer. Cell Death Dis. 2018, 9, 19. [CrossRef]

46. Ozretic, P.; Alvir, I.; Sarcevic, B.; Vujaskovic, Z.; Rendic-Miocevic, Z.; Roguljic, A.; Beketic-Oreskovic, L. Apoptosis regulator Bcl-2 is an independent prognostic marker for worse overall survival in triple-negative breast cancer patients. Int. J. Biol. Markers 2018, 33, 109-115. [CrossRef] [PubMed]

47. Balko, J.M.; Giltnane, J.M.; Wang, K.; Schwarz, L.J.; Young, C.D.; Cook, R.S.; Owens, P.; Sanders, M.E.; Kuba, M.G.; Sánchez, V.; et al. Molecular profiling of the residual disease of triple-negative breast cancers after neoadjuvant chemotherapy identifies actionable therapeutic targets. Cancer Discov. 2014, 4, 232-245. [CrossRef] [PubMed]

48. Wertz, I.E.; Kusam, S.; Lam, C.; Okamoto, T.; Sandoval, W.; Anderson, D.J.; Helgason, E.; Ernst, J.A.; Eby, M.; Liu, J.; et al Sensitivity to antitubulin chemotherapeutics is regulated by MCL1 and FBW7. Nature 2011, 471, 110-114. [CrossRef] [PubMed]

49. Park, H.S.; Jang, M.H.; Kim, E.J.; Kim, H.J.; Lee, H.J.; Kim, Y.J.; Kim, J.H.; Kang, E.; Kim, S.W.; Kim, I.A.; et al. High EGFR gene copy number predicts poor outcome in triple-negative breast cancer. Mod. Pathol. 2014, 27, 1212-1222. [CrossRef]

50. Porcelli, L.; Giovannetti, E.; Assaraf, Y.G.; Jansen, G.; Scheffer, G.L.; Kathman, I.; Azzariti, A.; Paradiso, A.; Peters, G.J. The EGFR pathway regulates BCRP expression in NSCLC cells: Role of erlotinib. Curr. Drug Targets 2014, 15, 1322-1330. [CrossRef]

51. Zhang, G.N.; Zhang, Y.K.; Wang, Y.J.; Gupta, P.; Ashby, C.R., Jr.; Alqahtani, S.; Deng, T.; Bates, S.E.; Kaddoumi, A.; Wurpel, J.N.D.; et al. Epidermal growth factor receptor (EGFR) inhibitor PD153035 reverses ABCG2-mediated multidrug resistance in non-small cell lung cancer: In vitro and in vivo. Cancer Lett. 2018, 424, 19-29. [CrossRef]

52. Yuan, J.; Yin, Z.; Tao, K.; Wang, G.; Gao, J. Function of insulin-like growth factor 1 receptor in cancer resistance to chemotherapy. Oncol. Lett. 2018, 15, 41-47. [CrossRef]

53. Farabaugh, S.M.; Boone, D.N.; Lee, A.V. Role of IGF1R in Breast Cancer Subtypes, Stemness, and Lineage Differentiation. Front. Endocrinol. 2015, 6, 59. [CrossRef] 
54. Jang, G.B.; Hong, I.S.; Kim, R.J.; Lee, S.Y.; Park, S.J.; Lee, E.S.; Park, J.H.; Yun, C.H.; Chung, J.U.; Lee, K.J.; et al. Wnt/ $\beta-C a t e n i n$ Small-Molecule Inhibitor CWP232228 Preferentially Inhibits the Growth of Breast Cancer Stem-like Cells. Cancer Res. 2015, 75, 1691-1702. [CrossRef] [PubMed]

55. Heskamp, S.; Boerman, O.C.; Molkenboer-Kuenen, J.D.; Wauters, C.A.; Strobbe, L.J.; Mandigers, C.M.; Bult, P.; Oyen, W.J.; van der Graaf, W.T.; van Laarhoven, H.W. Upregulation of IGF-1R expression during neoadjuvant therapy predicts poor outcome in breast cancer patients. PLoS ONE 2015, 10, e0117745. [CrossRef]

56. Cheng, Y.; Lin, L.; Li, X.; Lu, A.; Hou, C.; Wu, Q.; Hu, X.; Zhou, Z.; Chen, Z.; Tang, F. ADAM10 is involved in the oncogenic process and chemoresistance of triple-negative breast cancer via regulating Notch1 signaling pathway, CD44 and PrPc. Cancer Cell Int. 2021, 21, 32. [CrossRef] [PubMed]

57. Zhang, L.; Xu, X.; Su, X. Noncoding RNAs in cancer immunity: Functions, regulatory mechanisms, and clinical application. Mol. Cancer 2020, 19, 48. [CrossRef] [PubMed]

58. Xia, M.; Zu, X.; Chen, Z.; Wen, G.; Zhong, J. Noncoding RNAs in triple negative breast cancer: Mechanisms for chemoresistance Cancer Lett. 2021, 523, 100-110. [CrossRef]

59. Meyer, B.; Clifton, S.; Locke, W.; Luu, P.L.; Du, Q.; Lam, D.; Armstrong, N.J.; Kumar, B.; Deng, N.; Harvey, K.; et al. Identification of DNA methylation biomarkers with potential to predict response to neoadjuvant chemotherapy in triple-negative breast cancer Clin. Epigenet. 2021, 13, 226. [CrossRef]

60. Napieralski, R.; Schricker, G.; Auer, G.; Aubele, M.; Perkins, J.; Magdolen, V.; Ulm, K.; Hamann, M.; Walch, A.; Weichert, W.; et al. PITX2 DNA-Methylation: Predictive versus Prognostic Value for Anthracycline-Based Chemotherapy in Triple-Negative Breast Cancer Patients. Breast Care 2021, 16, 523-531. [CrossRef]

61. Gao, Y.; Wang, X.; Li, S.; Zhang, Z.; Li, X.; Lin, F. Identification of a DNA Methylation-Based Prognostic Signature for Patients with Triple-Negative Breast Cancer. Med. Sci. Monit. 2021, 27, e930025. [CrossRef]

62. Deng, X.; Kohanfars, M.; Hsu, H.M.; Souda, P.; Capri, J.; Whitelegge, J.P.; Chang, H.R. Combined phosphoproteomics and bioinformatics strategy in deciphering drug resistant related pathways in triple negative breast cancer. Int. J. Proteom. 2014, 2014, 1-12. [CrossRef]

63. Cheng, F.; Jia, P.; Wang, Q.; Zhao, Z. Quantitative network mapping of the human kinome interactome reveals new clues for rational kinase inhibitor discovery and individualized cancer therapy. Oncotarget 2014, 5, 3697-3710. [CrossRef]

64. Tzeng, Y.T.; Liu, P.F.; Li, J.Y.; Liu, L.F.; Kuo, S.Y.; Hsieh, C.W.; Lee, C.H.; Wu, C.H.; Hsiao, M.; Chang, H.T.; et al. Kinome-Wide siRNA Screening Identifies Src-Enhanced Resistance of Chemotherapeutic Drugs in Triple-Negative Breast Cancer Cells. Front. Pharmacol. 2018, 9, 1285. [CrossRef] [PubMed]

65. Foulkes, W.D.; Smith, I.E.; Reis-Filho, J.S. Triple-negative breast cancer. N. Engl. J. Med. 2010, 363, 1938-1948. [CrossRef] [PubMed]

66. Smith, A.L.; Robin, T.P.; Ford, H.L. Molecular pathways: Targeting the TGF- $\beta$ pathway for cancer therapy. Clin. Cancer Res. 2012, 18, 4514-4521. [CrossRef] [PubMed]

67. Neuzillet, C.; Tijeras-Raballand, A.; Cohen, R.; Cros, J.; Faivre, S.; Raymond, E.; de Gramont, A. Targeting the TGF $\beta$ pathway for cancer therapy. Pharmacol. Ther. 2015, 147, 22-31. [CrossRef] [PubMed]

68. Asiedu, M.K.; Ingle, J.N.; Behrens, M.D.; Radisky, D.C.; Knutson, K.L. TGFbeta/TNF(alpha)-mediated epithelial-mesenchymal transition generates breast cancer stem cells with a claudin-low phenotype. Cancer Res. 2011, 71, 4707-4719. [CrossRef]

69. Xu, X.; Zhang, L.; He, X.; Zhang, P.; Sun, C.; Xu, X.; Lu, Y.; Li, F. TGF- $\beta$ plays a vital role in triple-negative breast cancer (TNBC) drug-resistance through regulating stemness, EMT and apoptosis. Biochem. Biophys. Res. Commun. 2018, 502, 160-165. [CrossRef]

70. Harrison, H.; Farnie, G.; Howell, S.J.; Rock, R.E.; Stylianou, S.; Brennan, K.R.; Bundred, N.J.; Clarke, R.B. Regulation of breast cancer stem cell activity by signaling through the Notch4 receptor. Cancer Res. 2010, 70, 709-718. [CrossRef]

71. Kim, B.; Stephen, S.L.; Hanby, A.M.; Horgan, K.; Perry, S.L.; Richardson, J.; Roundhill, E.A.; Valleley, E.M.; Verghese, E.T.; Williams, B.J.; et al. Chemotherapy induces Notch1-dependent MRP1 upregulation, inhibition of which sensitizes breast cancer cells to chemotherapy. BMC Cancer 2015, 15, 634. [CrossRef]

72. Li, Z.L.; Chen, C.; Yang, Y.; Wang, C.; Yang, T.; Yang, X.; Liu, S.C. Gamma secretase inhibitor enhances sensitivity to doxorubicin in MDA-MB-231 cells. Int. J. Clin. Exp. Pathol. 2015, 8, 4378-4387.

73. Qiu, M.; Peng, Q.; Jiang, I.; Carroll, C.; Han, G.; Rymer, I.; Lippincott, J.; Zachwieja, J.; Gajiwala, K.; Kraynov, E.; et al. Specific inhibition of Notch1 signaling enhances the antitumor efficacy of chemotherapy in triple negative breast cancer through reduction of cancer stem cells. Cancer Lett. 2013, 328, 261-270. [CrossRef]

74. Ng, L.F.; Kaur, P.; Bunnag, N.; Suresh, J.; Sung, I.C.H.; Tan, Q.H.; Gruber, J.; Tolwinski, N.S. WNT Signaling in Disease. Cells 2019, 8, 826. [CrossRef] [PubMed]

75. Dey, N.; Barwick, B.G.; Moreno, C.S.; Ordanic-Kodani, M.; Chen, Z.; Oprea-Ilies, G.; Tang, W.; Catzavelos, C.; Kerstann, K.F.; Sledge, G.W., Jr.; et al. Wnt signaling in triple negative breast cancer is associated with metastasis. BMC Cancer 2013, $13,537$. [CrossRef]

76. Xu, J.; Prosperi, J.R.; Choudhury, N.; Olopade, O.I.; Goss, K.H. $\beta$-Catenin is required for the tumorigenic behavior of triplenegative breast cancer cells. PLoS ONE 2015, 10, e0117097. [CrossRef] [PubMed]

77. Shen, H.; Yan, W.; Yuan, J.; Wang, Z.; Wang, C. Nek2B activates the wnt pathway and promotes triple-negative breast cancer chemotherapy-resistance by stabilizing $\beta$-catenin. J. Exp. Clin. Cancer Res. 2019, 38, 243. [CrossRef] [PubMed]

78. Yin, S.; Xu, L.; Bonfil, R.D.; Banerjee, S.; Sarkar, F.H.; Sethi, S.; Reddy, K.B. Tumor-initiating cells and FZD8 play a major role in drug resistance in triple-negative breast cancer. Mol. Cancer Ther. 2013, 12, 491-498. [CrossRef] [PubMed] 
79. Harris, L.G.; Pannell, L.K.; Singh, S.; Samant, R.S.; Shevde, L.A. Increased vascularity and spontaneous metastasis of breast cancer by hedgehog signaling mediated upregulation of cyr61. Oncogene 2012, 31, 3370-3380. [CrossRef]

80. Skoda, A.M.; Simovic, D.; Karin, V.; Kardum, V.; Vranic, S.; Serman, L. The role of the Hedgehog signaling pathway in cancer, A comprehensive review. Bosn. J. Basic Med. Sci. 2018, 18, 8-20. [CrossRef]

81. Sims-Mourtada, J.; Opdenaker, L.M.; Davis, J.; Arnold, K.M.; Flynn, D. Taxane-induced hedgehog signaling is linked to expansion of breast cancer stem-like populations after chemotherapy. Mol. Carcinog. 2015, 54, 1480-1493. [CrossRef]

82. Arnold, K.M.; Pohlig, R.T.; Sims-Mourtada, J. Co-activation of Hedgehog and Wnt signaling pathways is associated with poor outcomes in triple negative breast cancer. Oncol. Lett. 2017, 14, 5285-5292. [CrossRef]

83. Fan, Y.; Dutta, J.; Gupta, N.; Fan, G.; Gélinas, C. Regulation of programmed cell death by NF-kappaB and its role in tumorigenesis and therapy. Adv. Exp. Med. Biol. 2008, 615, 223-250.

84. Ossovskaya, V.; Wang, Y.; Budoff, A.; Xu, Q.; Lituev, A.; Potapova, O.; Vansant, G.; Monforte, J.; Daraselia, N. Exploring molecular pathways of triple-negative breast cancer. Genes Cancer 2011, 2, 870-879. [CrossRef] [PubMed]

85. D'Ignazio, L.; Rocha, S. Hypoxia Induced NF-kB. Cells 2016, 5, 10. [CrossRef] [PubMed]

86. Tang, D.; Ma, J.; Chu, Z.; Wang, X.; Zhao, W.; Zhang, Q. Apatinib-induced NF-кB inactivation sensitizes triple-negative breast cancer cells to doxorubicin. Am. J. Transl. Res. 2020, 12, 3741-3753. [PubMed]

87. Ellis, H.; Ma, C.X. PI3K Inhibitors in Breast Cancer Therapy. Curr. Oncol. Rep. 2019, 21, 110. [CrossRef] [PubMed]

88. Li, L.; Ross, A.H. Why is PTEN an important tumor suppressor? J. Cell Biochem. 2007, 102, 1368-1374. [CrossRef] [PubMed]

89. Ueng, S.H.; Chen, S.C.; Chang, Y.S.; Hsueh, S.; Lin, Y.C.; Chien, H.P.; Lo, Y.F.; Shen, S.C.; Hsueh, C. Phosphorylated mTOR expression correlates with poor outcome in early-stage triple negative breast carcinomas. Int. J. Clin. Exp. Pathol. 2012, 5, 806-813.

90. Steelman, L.S.; Navolanic, P.M.; Sokolosky, M.L.; Taylor, J.R.; Lehmann, B.D.; Chappell, W.H.; Abrams, S.L.; Wong, E.W.; Stadelman, K.M.; Terrian, D.M.; et al. Suppression of PTEN function increases breast cancer chemotherapeutic drug resistance while conferring sensitivity to mTOR inhibitors. Oncogene 2008, 27, 4086-4095. [CrossRef]

91. Guanizo, A.C.; Fernando, C.D.; Garama, D.J.; Gough, D.J. STAT3: A multifaceted oncoprotein. Growth Factors 2018, 36, 1-14. [CrossRef]

92. Hartman, Z.C.; Poage, G.M.; den Hollander, P.; Tsimelzon, A.; Hill, J.; Panupinthu, N.; Zhang, Y.; Mazumdar, A.; Hilsenbeck, S.G.; Mills, G.B.; et al. Growth of triple-negative breast cancer cells relies upon coordinate autocrine expression of the proinflammatory cytokines IL-6 and IL-8. Cancer Res. 2013, 73, 3470-3480. [CrossRef]

93. Wei, W.; Tweardy, D.J.; Zhang, M.; Zhang, X.; Landua, J.; Petrovic, I.; Bu, W.; Roarty, K.; Hilsenbeck, S.G.; Rosen, J.M.; et al. STAT3 signaling is activated preferentially in tumor-initiating cells in claudin-low models of human breast cancer. Stem Cells 2014, 32, 2571-2582. [CrossRef]

94. Sirkisoon, S.R.; Carpenter, R.L.; Rimkus, T.; Anderson, A.; Harrison, A.; Lange, A.M.; Jin, G.; Watabe, K.; Lo, H.W. Interaction between STAT3 and GLI1/tGLI1 oncogenic transcription factors promotes the aggressiveness of triple-negative breast cancers and HER2-enriched breast cancer. Oncogene 2018, 37, 2502-2514. [CrossRef] [PubMed]

95. Kuo, W.Y.; Hwu, L.; Wu, C.Y.; Lee, J.S.; Chang, C.W.; Liu, R.S. STAT3/NF-kB-Regulated Lentiviral TK/GCV Suicide Gene Therapy for Cisplatin-Resistant Triple-Negative Breast Cancer. Theranostics 2017, 7, 647-663. [CrossRef] [PubMed]

96. Moreira, M.P.; da Conceição Braga, L.; Cassali, G.D.; Silva, L.M. STAT3 as a promising chemoresistance biomarker associated with the CD44+/high/CD24-/low/ALDH+ BCSCs-like subset of the triple-negative breast cancer (TNBC) cell line. Exp. Cell Res. 2018, 363, 283-290. [CrossRef] [PubMed]

97. Soleymani Abyaneh, H.; Gupta, N.; Radziwon-Balicka, A.; Jurasz, P.; Seubert, J.; Lai, R.; Lavasanifar, A. STAT3 but Not HIF-1 $\alpha$ Is Important in Mediating Hypoxia-Induced Chemoresistance in MDA-MB-231, a Triple Negative Breast Cancer Cell Line. Cancers 2017, 9, 137. [CrossRef]

98. Montagna, E.; Maisonneuve, P.; Rotmensz, N.; Cancello, G.; Iorfida, M.; Balduzzi, A.; Galimberti, V.; Veronesi, P.; Luini, A.; Pruneri, G.; et al. Heterogeneity of triple-negative breast cancer: Histologic subtyping to inform the outcome. Clin. Breast Cancer 2013, 13, 31-39. [CrossRef]

99. Tadros, A.B.; Sevilimedu, V.; Giri, D.D.; Zabor, E.C.; Morrow, M.; Plitas, G. Survival Outcomes for Metaplastic Breast Cancer Differ by Histologic Subtype. Ann. Surg. Oncol. 2021, 28, 4245-4253. [CrossRef]

100. Corso, G.; Frassoni, S.; Girardi, A.; de Camilli, E.; Montagna, E.; Intra, M.; Bottiglieri, L.; Margherita de Scalzi, A.; Fanianos, D.M.; Magnoni, F.; et al. Metaplastic breast cancer: Prognostic and therapeutic considerations. J. Surg. Oncol. 2021, 123, 61-70. [CrossRef]

101. Kalaw, E.; Lim, M.; Kutasovic, J.R.; Sokolova, A.; Taege, L.; Johnstone, K.; Bennett, J.; Saunus, J.M.; Niland, C.; Ferguson, K.; et al. Metaplastic breast cancers frequently express immune checkpoint markers FOXP3 and PD-L1. Br. J. Cancer 2020, 123, 1665-1672. [CrossRef]

102. Lehmann, B.D.; Bauer, J.A.; Chen, X.; Sanders, M.E.; Chakravarthy, A.B.; Shyr, Y.; Pietenpol, J.A. Identification of human triple-negative breast cancer subtypes and preclinical models for selection of targeted therapies. J. Clin. Investig. 2011, 121, 2750-2767. [CrossRef]

103. Lehmann, B.D.; Jovanović, B.; Chen, X.; Estrada, M.V.; Johnson, K.N.; Shyr, Y.; Moses, H.L.; Sanders, M.E.; Pietenpol, J.A Refinement of Triple-Negative Breast Cancer Molecular Subtypes: Implications for Neoadjuvant Chemotherapy Selection. PLoS ONE 2016, 11, e0157368. [CrossRef] 
104. Echavarria, I.; López-Tarruella, S.; Picornell, A.; García-Saenz, J.Á.; Jerez, Y.; Hoadley, K.; Gómez, H.L.; Moreno, F.; Monte-Millan, M.D.; Márquez-Rodas, I.; et al. Pathological Response in a Triple-Negative Breast Cancer Cohort Treated with Neoadjuvant Carboplatin and Docetaxel According to Lehmann's Refined Classification. Clin. Cancer Res. 2018, 24, 1845-1852. [CrossRef]

105. Loibl, S.; Müller, B.M.; von Minckwitz, G.; Schwabe, M.; Roller, M.; Darb-Esfahani, S.; Ataseven, B.; du Bois, A.; Fissler-Eckhoff, A.; Gerber, B.; et al. Androgen receptor expression in primary breast cancer and its predictive and prognostic value in patients treated with neoadjuvant chemotherapy. Breast Cancer Res. Treat. 2011, 130, 477-487. [CrossRef] [PubMed]

106. Asghar, U.S.; Barr, A.R.; Cutts, R.; Beaney, M.; Babina, I.; Sampath, D.; Giltnane, J.; Lacap, J.A.; Crocker, L.; Young, A.; et al. Single-Cell Dynamics Determines Response to CDK4/6 Inhibition in Triple-Negative Breast Cancer. Clin. Cancer Res. 2017, 23, 5561-5572. [CrossRef] [PubMed]

107. Denkert, C.; von Minckwitz, G.; Darb-Esfahani, S.; Lederer, B.; Heppner, B.I.; Weber, K.E.; Budczies, J.; Huober, J.; Klauschen, F.; Furlanetto, J.; et al. Tumour-infiltrating lymphocytes and prognosis in different subtypes of breast cancer: A pooled analysis of 3771 patients treated with neoadjuvant therapy. Lancet Oncol. 2018, 19, 40-50. [CrossRef]

108. Ono, M.; Tsuda, H.; Shimizu, C.; Yamamoto, S.; Shibata, T.; Yamamoto, H.; Hirata, T.; Yonemori, K.; Ando, M.; Tamura, K.; et al. Tumor-infiltrating lymphocytes are correlated with response to neoadjuvant chemotherapy in triple-negative breast cancer. Breast Cancer Res. Treat. 2012, 132, 793-805. [CrossRef]

109. Oda, N.; Shimazu, K.; Naoi, Y.; Morimoto, K.; Shimomura, A.; Shimoda, M.; Kagara, N.; Maruyama, N.; Kim, S.J.; Noguchi, S Intratumoral regulatory $\mathrm{T}$ cells as an independent predictive factor for pathological complete response to neoadjuvant paclitaxel followed by 5-FU/epirubicin/cyclophosphamide in breast cancer patients. Breast Cancer Res. Treat. 2012, 136, 107-116. [CrossRef]

110. Loi, S.; Drubay, D.; Adams, S.; Pruneri, G.; Francis, P.A.; Lacroix-Triki, M.; Joensuu, H.; Dieci, M.V.; Badve, S.; Demaria, S.; et al Tumor-Infiltrating Lymphocytes and Prognosis: A Pooled Individual Patient Analysis of Early-Stage Triple-Negative Breast Cancers. J. Clin. Oncol. 2019, 37, 559-569. [CrossRef] [PubMed]

111. Cerbelli, B.; Scagnoli, S.; Mezi, S.; de Luca, A.; Pisegna, S.; Amabile, M.I.; Roberto, M.; Fortunato, L.; Costarelli, L.; Pernazza, A.; et al. Tissue Immune Profile: A Tool to Predict Response to Neoadjuvant Therapy in Triple Negative Breast Cancer. Cancers 2020, 12, 2648. [CrossRef]

112. Brown, J.R.; Wimberly, H.; Lannin, D.R.; Nixon, C.; Rimm, D.L.; Bossuyt, V. Multiplexed quantitative analysis of CD3, CD8, and CD20 predicts response to neoadjuvant chemotherapy in breast cancer. Clin. Cancer Res. 2014, 20, 5995-6005. [CrossRef]

113. Seo, A.N.; Lee, H.J.; Kim, E.J.; Kim, H.J.; Jang, M.H.; Lee, H.E.; Kim, Y.J.; Kim, J.H.; Park, S.Y. Tumour-infiltrating CD8+ lymphocytes as an independent predictive factor for pathological complete response to primary systemic therapy in breast cancer. Br. J. Cancer 2013, 109, 2705-2713. [CrossRef]

114. Verma, C.; Kaewkangsadan, V.; Eremin, J.M.; Cowley, G.P.; Ilyas, M.; El-Sheemy, M.A.; Eremin, O. Natural killer (NK) cell profiles in blood and tumour in women with large and locally advanced breast cancer (LLABC) and their contribution to a pathological complete response (PCR) in the tumour following neoadjuvant chemotherapy (NAC): Differential restoration of blood profiles by NAC and surgery. J. Transl. Med. 2015, 13, 180. [PubMed]

115. Kim, R.; Kawai, A.; Wakisaka, M.; Funaoka, Y.; Yasuda, N.; Hidaka, M.; Morita, Y.; Ohtani, S.; Ito, M.; Arihiro, K. A potential role for peripheral natural killer cell activity induced by preoperative chemotherapy in breast cancer patients. Cancer Immunol. Immunother. 2019, 68, 577-585. [CrossRef] [PubMed]

116. Ascierto, M.L.; Idowu, M.O.; Zhao, Y.; Khalak, H.; Payne, K.K.; Wang, X.Y.; Dumur, C.I.; Bedognetti, D.; Tomei, S.; Ascierto, P.A.; et al. Molecular signatures mostly associated with NK cells are predictive of relapse free survival in breast cancer patients. $J$. Transl. Med. 2013, 11, 145. [CrossRef] [PubMed]

117. Garcia-Chagollan, M.; Carranza-Torres, I.E.; Carranza-Rosales, P.; Guzmán-Delgado, N.E.; Ramírez-Montoya, H.; Martínez-Silva, M.G.; Mariscal-Ramirez, I.; Barrón-Gallardo, C.A.; Pereira-Suárez, A.L.; Aguilar-Lemarroy, A.; et al. Expression of NK Cell Surface Receptors in Breast Cancer Tissue as Predictors of Resistance to Antineoplastic Treatment. Technol. Cancer Res. Treat. 2018, 17, 1533033818764499. [CrossRef]

118. Antonio, N.; Bønnelykke-Behrndtz, M.L.; Ward, L.C.; Collin, J.; Christensen, I.J.; Steiniche, T.; Schmidt, H.; Feng, Y.; Martin, P. The wound inflammatory response exacerbates growth of pre-neoplastic cells and progression to cancer. EMBO J. 2015, 34, 2219-2236. [CrossRef]

119. Kaewkangsadan, V.; Verma, C.; Eremin, J.M.; Cowley, G.; Ilyas, M.; Satthaporn, S.; Eremin, O. The Differential Contribution of the Innate Immune System to a Good Pathological Response in the Breast and Axillary Lymph Nodes Induced by Neoadjuvant Chemotherapy in Women with Large and Locally Advanced Breast Cancers. J. Immunol. Res. 2017, 2017, 1049023. [CrossRef]

120. Fitzpatrick, A.; Tutt, A. Controversial issues in the neoadjuvant treatment of triple-negative breast cancer. Ther. Adv. Med. Oncol. 2019, 11, 1758835919882581. [CrossRef]

121. Du, C.; Wang, Y.; Zhang, Y.; Zhang, J.; Zhang, L.; Li, J. LncRNA DLX6-AS1 Contributes to Epithelial-Mesenchymal Transition and Cisplatin Resistance in Triple-negative Breast Cancer via Modulating Mir-199b-5p/Paxillin Axis. Cell Transplant. 2020, 29 , 963689720929983. [CrossRef]

122. Li, H.Y.; Liang, J.L.; Kuo, Y.L.; Lee, H.H.; Calkins, M.J.; Chang, H.T.; Lin, F.C.; Chen, Y.C.; Hsu, T.I.; Hsiao, M.; et al. miR-105/93-3p promotes chemoresistance and circulating miR-105/93-3p acts as a diagnostic biomarker for triple negative breast cancer. Breast Cancer Res. 2017, 19, 133. [CrossRef]

123. Kahraman, M.; Röske, A.; Laufer, T.; Fehlmann, T.; Backes, C.; Kern, F.; Kohlhaas, J.; Schrörs, H.; Saiz, A.; Zabler, C.; et al. MicroRNA in diagnosis and therapy monitoring of early-stage triple-negative breast cancer. Sci. Rep. 2018, 8, 11584. [CrossRef] 
124. Sukumar, J.; Gast, K.; Quiroga, D.; Lustberg, M.; Williams, N. Triple-negative breast cancer: Promising prognostic biomarkers currently in development. Expert Rev. Anticancer. Ther. 2021, 21, 135-148. [CrossRef] [PubMed]

125. Kosaka, Y.; Yamamoto, Y.; Tanino, H.; Nishimiya, H.; Yamamoto-Ibusuki, M.; Hirota, Y.; Iwase, H.; Nakamura, S.; Akashi-Tanaka, S. BRCAness as an Important Prognostic Marker in Patients with Triple-Negative Breast Cancer Treated with Neoadjuvant Chemotherapy: A Multicenter Retrospective Study. Diagnostics 2020, 10, 119. [CrossRef] [PubMed]

126. Lord, C.J.; Ashworth, A. BRCAness revisited. Nat. Rev. Cancer 2016, 16, 110-120. [CrossRef] [PubMed]

127. Lin, P.H.; Chen, M.; Tsai, L.W.; Lo, C.; Yen, T.C.; Huang, T.Y.; Chen, C.K.; Fan, S.C.; Kuo, S.H.; Huang, C.S. Using next-generation sequencing to redefine BRCAness in triple-negative breast cancer. Cancer Sci. 2020, 111, 1375-1384. [CrossRef] [PubMed]

128. Timms, K.M.; Abkevich, V.; Hughes, E.; Neff, C.; Reid, J.; Morris, B.; Kalva, S.; Potter, J.; Tran, T.V.; Chen, J.; et al. Association of BRCA1/2 defects with genomic scores predictive of DNA damage repair deficiency among breast cancer subtypes. Breast Cancer Res. 2014, 16, 475. [CrossRef]

129. Telli, M.L.; Hellyer, J.; Audeh, W.; Jensen, K.C.; Bose, S.; Timms, K.M.; Gutin, A.; Abkevich, V.; Peterson, R.N.; Neff, C.; et al Homologous recombination deficiency (HRD) status predicts response to standard neoadjuvant chemotherapy in patients with triple-negative or BRCA1/2 mutation-associated breast cancer. Breast Cancer Res. Treat. 2018, 168, 625-630. [CrossRef]

130. Jin, J.; Zhang, W.; Ji, W.; Yang, F.; Guan, X. Predictive biomarkers for triple negative breast cancer treated with platinum-based chemotherapy. Cancer Biol. Ther. 2017, 18, 369-378. [CrossRef]

131. Loibl, S.; Weber, K.E.; Timms, K.M.; Elkin, E.P.; Hahnen, E.; Fasching, P.A.; Lederer, B.; Denkert, C.; Schneeweiss, A.; Braun, S.; et al. Survival analysis of carboplatin added to an anthracycline/taxane-based neoadjuvant chemotherapy and HRD score as predictor of response-final results from GeparSixto. Ann. Oncol. 2018, 29, 2341-2347. [CrossRef]

132. Kaklamani, V.G.; Jeruss, J.S.; Hughes, E.; Siziopikou, K.; Timms, K.M.; Gutin, A.; Abkevich, V.; Sangale, Z.; Solimeno, C.; Brown, K.L.; et al. Phase II neoadjuvant clinical trial of carboplatin and eribulin in women with triple negative early-stage breast cancer (NCT01372579). Breast Cancer Res. Treat. 2015, 151, 629-638. [CrossRef]

133. Teraoka, S.; Muguruma, M.; Takano, N.; Miyahara, K.; Kawate, T.; Kaise, H.; Yamada, K.; Miyazawa, K.; Ishikawa, T. Association of BRCA Mutations and BRCAness Status with Anticancer Drug Sensitivities in Triple-Negative Breast Cancer Cell Lines. J. Surg. Res. 2020, 250, 200-208. [CrossRef]

134. Liu, L.; Matsunaga, Y.; Tsurutani, J.; Akashi-Tanaka, S.; Masuda, H.; Ide, Y.; Hashimoto, R.; Inuzuka, M.; Watanabe, C.; Taruno, K.; et al. BRCAness as a prognostic indicator in patients with early breast cancer. Sci. Rep. 2020, 10, 21173. [CrossRef] [PubMed]

135. Jurj, A.; Pop, L.A.; Zanoaga, O.; Ciocan-Cârtiţă, C.A.; Cojocneanu, R.; Moldovan, C.; Raduly, L.; Pop-Bica, C.; Trif, M.; Irimie, A.; et al. New Insights in Gene Expression Alteration as Effect of Paclitaxel Drug Resistance in Triple Negative Breast Cancer Cells. Cell Physiol. Biochem. 2020, 54, 648-664.

136. Wang, R.X.; Ji, P.; Gong, Y.; Shao, Z.M.; Chen, S. Value of CXCL8-CXCR1/2 axis in neoadjuvant chemotherapy for triple-negative breast cancer patients: A retrospective pilot study. Breast Cancer Res. Treat. 2020, 181, 561-570. [CrossRef] [PubMed]

137. Liu, X.Y.; Jiang, W.; Ma, D.; Ge, L.P.; Yang, Y.S.; Gou, Z.C.; Xu, X.E.; Shao, Z.M.; Jiang, Y.Z. SYTL4 downregulates microtubule stability and confers paclitaxel resistance in triple-negative breast cancer. Theranostics 2020, 10, 10940-10956. [CrossRef] [PubMed]

138. Lian, B.; Pei, Y.C.; Jiang, Y.Z.; Xue, M.Z.; Li, D.Q.; Li, X.G.; Zheng, Y.Z.; Liu, X.Y.; Qiao, F.; Sun, W.L.; et al. Truncated HDAC9 identified by integrated genome-wide screen as the key modulator for paclitaxel resistance in triple-negative breast cancer. Theranostics 2020, 10, 11092-11109. [CrossRef]

139. Zhang, Q.; Lei, L.; Jing, D. Knockdown of SERPINE1 reverses resistance of triple-negative breast cancer to paclitaxel via suppression of VEGFA. Oncol. Rep. 2020, 44, 1875-1884. [CrossRef] [PubMed]

140. Lin, H.Y.; Kuei, C.H.; Lee, H.H.; Lin, C.H.; Chen, Y.L.; Chen, C.L.; Lin, Y.F. TNFSF13 upregulation confers chemotherapeutic resistance via triggering autophagy initiation in triple-negative breast cancer. J. Mol. Med. 2020, 98, 1255-1267. [CrossRef]

141. Liu, M.; Gong, C.; Xu, R.; Chen, Y.; Wang, X. MicroRNA-5195-3p enhances the chemosensitivity of triple-negative breast cancer to paclitaxel by downregulating EIF4A2. Cell Mol. Biol. Lett. 2019, 24, 47. [CrossRef]

142. Sha, L.Y.; Zhang, Y.; Wang, W.; Sui, X.; Liu, S.K.; Wang, T.; Zhang, H. MiR-18a upregulation decreases Dicer expression and confers paclitaxel resistance in triple negative breast cancer. Eur. Rev. Med. Pharmacol Sci. 2016, 20, 2201-2208.

143. Hou, X.; Niu, Z.; Liu, L.; Guo, Q.; Li, H.; Yang, X.; Zhang, X. miR-1207-5p regulates the sensitivity of triple-negative breast cancer cells to Taxol treatment via the suppression of LZTS1 expression. Oncol. Lett. 2019, 17, 990-998. [CrossRef]

144. Shaath, H.; Vishnubalaji, R.; Elango, R.; Khattak, S.; Alajez, N.M. Single-cell long noncoding RNA (lncRNA) transcriptome implicates MALAT1 in triple-negative breast cancer (TNBC) resistance to neoadjuvant chemotherapy. Cell Death Discov. 2021, 7, 23. [CrossRef] [PubMed]

145. Bornancin, F. Ceramide kinase: The first decade. Cell Signal. 2011, 23, 999-1008. [CrossRef] [PubMed]

146. Gomez-Munoz, A. The role of ceramide 1-phosphate in tumor cell survival and dissemination. Adv. Cancer Res. 2018, 140, 217-234. [PubMed]

147. Galadari, S.; Rahman, A.; Pallichankandy, S.; Thayyullathil, F. Tumor suppressive functions of ceramide: Evidence and mechanisms. Apoptosis 2015, 20, 689-711. [CrossRef]

148. Che, J.; Huang, Y.; Xu, C.; Zhang, P. Increased ceramide production sensitizes breast cancer cell response to chemotherapy. Cancer Chemother. Pharmacol. 2017, 79, 933-941. [CrossRef] 
149. Zhu, S.; Xu, Y.; Wang, L.; Liao, S.; Wang, Y.; Shi, M.; Tu, Y.; Zhou, Y.; Wei, W. Ceramide kinase mediates intrinsic resistance and inferior response to chemotherapy in triple-negative breast cancer by upregulating Ras/ERK and PI3K/Akt pathways. Cancer Cell Int. 2021, 21, 42. [CrossRef]

150. Murray, A.S.; Hyland, T.E.; Sala-Hamrick, K.E.; Mackinder, J.R.; Martin, C.E.; Tanabe, L.M.; Varela, F.A.; List, K. The cell-surface anchored serine protease TMPRSS13 promotes breast cancer progression and resistance to chemotherapy. Oncogene 2020, 39, 6421-6436. [CrossRef]

151. Kong, D.D.; Fu, R.Z.; Li, L.; Wang, W.; Wang, S.B. Association between the methylation status of PCDH17 and the efficacy of neoadjuvant chemotherapy in triple-negative breast cancer. Oncol. Lett. 2020, 20, 1649-1656. [CrossRef]

152. Zhang, X.; Li, J.; Yang, Q.; Wang, Y.; Li, X.; Liu, Y.; Shan, B. Tumor mutation burden and JARID2 gene alteration are associated with short disease-free survival in locally advanced triple-negative breast cancer. Ann. Transl. Med. 2020, 8, 1052. [CrossRef]

153. Dou, D.; Ren, X.; Han, M.; Xu, X.; Ge, X.; Gu, Y.; Wang, X.; Zhao, S. CircUBE2D2 (hsa_circ_0005728) promotes cell proliferation, metastasis and chemoresistance in triple-negative breast cancer by regulating miR-512-3p/CDCA3 axis. Cancer Cell Int. 2020, 20, 454. [CrossRef]

154. Tormo, E.; Ballester, S.; Adam-Artigues, A.; Burgués, O.; Alonso, E.; Bermejo, B.; Menéndez, S.; Zazo, S.; Madoz-Gúrpide, J.; Rovira, A.; et al. The miRNA-449 family mediates doxorubicin resistance in triple-negative breast cancer by regulating cell cycle factors. Sci. Rep. 2019, 9, 5316. [CrossRef] [PubMed]

155. Li, Y.; Liang, Y.; Sang, Y.; Song, X.; Zhang, H.; Liu, Y.; Jiang, L.; Yang, Q. MiR-770 suppresses the chemoresistance and metastasis of triple negative breast cancer via direct targeting of STMN1. Cell Death Dis. 2018, 9, 14. [CrossRef] [PubMed]

156. Piasecka, D.; Braun, M.; Kordek, R.; Sadej, R.; Romanska, H. MicroRNAs in regulation of triple-negative breast cancer progression. J. Cancer Res. Clin. Oncol. 2018, 144, 1401-1411. [CrossRef] [PubMed]

157. Ciocan-Cartita, C.A.; Jurj, A.; Zanoaga, O.; Cojocneanu, R.; Pop, L.A.; Moldovan, A.; Moldovan, C.; Zimta, A.A.; Raduly, L.; Pop-Bica, C.; et al. New insights in gene expression alteration as effect of doxorubicin drug resistance in triple negative breast cancer cells. J. Exp. Clin. Cancer Res. 2020, 39, 241. [CrossRef]

158. Luo, Y.; Zhang, W.; Xu, L.; Chen, Y.; Xu, Y.; Yuan, L. Long Non-Coding RNA PVT1 Regulates the Resistance of the Breast Cancer Cell Line MDA-MB-231 to Doxorubicin via Nrf2. Technol. Cancer Res. Treat. 2020, 19, 1533033820980763. [CrossRef]

159. Przanowski, P.; Lou, S.; Tihagam, R.D.; Mondal, T.; Conlan, C.; Shivange, G.; Saltani, I.; Singh, C.; Xing, K.; Morris, B.B.; et al. Oncogenic TRIM37 Links Chemoresistance and Metastatic Fate in Triple-Negative Breast Cancer. Cancer Res. 2020, 80, 4791-4804. [CrossRef]

160. Zheng, Q.; Yao, D.; Cai, Y.; Zhou, T. NLRP3 augmented resistance to gemcitabine in triple-negative breast cancer cells via EMT/IL-1 $\beta / W n t / \beta$-catenin signaling pathway. Biosci. Rep. 2020, 40, BSR20200730. [CrossRef]

161. Wu, C.; Zhao, A.; Tan, T.; Wang, Y.; Shen, Z. Overexpression of microRNA-620 facilitates the resistance of triple negative breast cancer cells to gemcitabine treatment by targeting DCTD. Exp. Ther. Med. 2019, 18, 550-558. [CrossRef]

162. Elsharawy, K.A.; Althobiti, M.; Mohammed, O.J.; Aljohani, A.I.; Toss, M.S.; Green, A.R.; Rakha, E.A. Nucleolar protein 10 (NOP10) predicts poor prognosis in invasive breast cancer. Breast Cancer Res. Treat. 2021, 185, 615-627. [CrossRef]

163. Damaskos, C.; Garmpis, N.; Garmpi, A.; Nikolettos, K.; Sarantis, P.; Georgakopoulou, V.E.; Nonni, A.; Schizas, D.; Antoniou, E.A.; Karamouzis, M.V.; et al. Investigational Drug Treatments for Triple-Negative Breast Cancer. J. Pers. Med. 2021, 11, 652. [CrossRef]

164. Copson, E.R.; Maishman, T.C.; Tapper, W.J.; Cutress, R.I.; Greville-Heygate, S.; Altman, D.G.; Eccles, B.; Gerty, S.; Durcan, L.T.; Jones, L.; et al. Germline BRCA mutation and outcome in young-onset breast cancer (POSH): A prospective cohort study. Lancet Oncol. 2018, 19, 169-180. [CrossRef]

165. Robson, M.; Im, S.A.; Senkus, E.; Xu, B.; Domchek, S.M.; Masuda, N.; Delaloge, S.; Li, W.; Tung, N.; Armstrong, A.; et al. Olaparib for Metastatic Breast Cancer in Patients with a Germline BRCA Mutation. N. Engl. J. Med. 2017, 377, 523-533. [CrossRef] [PubMed]

166. Litton, J.K.; Rugo, H.S.; Ettl, J.; Hurvitz, S.A.; Gonçalves, A.; Lee, K.H.; Fehrenbacher, L.; Yerushalmi, R.; Mina, L.A.; Martin, M.; et al. Talazoparib in Patients with Advanced Breast Cancer and a Germline BRCA Mutation. N. Engl. J. Med. 2018, 379, 753-763. [CrossRef] [PubMed]

167. Eikesdal, H.P.; Yndestad, S.; Elzawahry, A.; Llop-Guevara, A.; Gilje, B.; Blix, E.S.; Espelid, H.; Lundgren, S.; Geisler, J.; Vagstad, G.; et al. Olaparib monotherapy as primary treatment in unselected triple negative breast cancer. Ann. Oncol. 2021, 32, 240-249. [CrossRef]

168. Fasching, P.A.; Link, T.; Hauke, J.; Seither, F.; Jackisch, C.; Klare, P.; Schmatloch, S.; Hanusch, C.; Huober, J.; Stefek, A.; et al. Neoadjuvant paclitaxel/olaparib in comparison to paclitaxel/carboplatinum in patients with HER2-negative breast cancer and homologous recombination deficiency (GeparOLA study). Ann. Oncol. 2021, 32, 49-57. [CrossRef]

169. Litton, J.K.; Scoggins, M.E.; Hess, K.R.; Adrada, B.E.; Murthy, R.K.; Damodaran, S.; DeSnyder, S.M.; Brewster, A.M.; Barcenas, C.H.; Valero, V.; et al. Neoadjuvant Talazoparib for Patients with Operable Breast Cancer with a Germline BRCA Pathogenic Variant. J. Clin. Oncol. 2020, 38, 388-394. [CrossRef]

170. Drilon, A.; Laetsch, T.W.; Kummar, S.; DuBois, S.G.; Lassen, U.N.; Demetri, G.D.; Nathenson, M.; Doebele, R.C.; Farago, A.F.; Pappo, A.S.; et al. Efficacy of Larotrectinib in TRK Fusion-Positive Cancers in Adults and Children. N. Engl. J. Med. 2018, 378, 731-739. [CrossRef] 
171. Hong, D.S.; DuBois, S.G.; Kummar, S.; Farago, A.F.; Albert, C.M.; Rohrberg, K.S.; van Tilburg, C.M.; Nagasubramanian, R.; Berlin, J.D.; Federman, N.; et al. Larotrectinib in patients with TRK fusion-positive solid tumours: A pooled analysis of three phase $1 / 2$ clinical trials. Lancet Oncol. 2020, 21, 531-540. [CrossRef]

172. Doebele, R.C.; Drilon, A.; Paz-Ares, L.; Siena, S.; Shaw, A.T.; Farago, A.F.; Blakely, C.M.; Seto, T.; Cho, B.C.; Tosi, D.; et al Entrectinib in patients with advanced or metastatic NTRK fusion-positive solid tumours: Integrated analysis of three phase 1-2 trials. Lancet Oncol. 2020, 21, 271-282. [CrossRef]

173. Ross, J.S.; Chung, J.H.; Elvin, J.A.; Vergilio, J.; Ramkissoon, S.H.; Suh, J.H.; Severson, E.; Daniel, S.; Frampton, G.M.; Fabrizio, D.A.; et al. NTRK fusions in breast cancer: Clinical, pathologic and genomic findings. Cancer Res. 2018, 78, P2-09-15. [CrossRef]

174. Jacob, J.D.; Hodge, C.; Franko, J.; Pezzi, C.M.; Goldman, C.D.; Klimberg, V.S. Rare breast cancer: 246 invasive secretory carcinomas from the National Cancer Data Base. J. Surg. Oncol. 2016, 113, 721-725. [CrossRef] [PubMed]

175. Tognon, C.; Knezevich, S.R.; Huntsman, D.; Roskelley, C.D.; Melnyk, N.; Mathers, J.A.; Becker, L.; Carneiro, F.; MacPherson, N.; Horsman, D.; et al. Expression of the ETV6-NTRK3 gene fusion as a primary event in human secretory breast carcinoma. Cancer Cell 2002, 2, 367-376. [CrossRef]

176. Krings, G.; Joseph, N.M.; Bean, G.R.; Solomon, D.; Onodera, C.; Talevich, E.; Yeh, I.; Grenert, J.P.; Hosfield, E.; Crawford, E.D.; et al. Genomic profiling of breast secretory carcinomas reveals distinct genetics from other breast cancers and similarity to mammary analog secretory carcinomas. Mod. Pathol. 2017, 30, 1086-1099. [CrossRef] [PubMed]

177. Laé, M.; Fréneaux, P.; Sastre-Garau, X.; Chouchane, O.; Sigal-Zafrani, B.; Vincent-Salomon, A. Secretory breast carcinomas with ETV6-NTRK3 fusion gene belong to the basal-like carcinoma spectrum. Mod. Pathol. 2009, 22, 291-298. [CrossRef]

178. Hoda, R.S.; Brogi, E.; Pareja, F.; Nanjangud, G.; Murray, M.P.; Weigelt, B.; Reis-Filho, J.S.; Wen, H.Y. Secretory carcinoma of the breast: Clinicopathologic profile of 14 cases emphasising distant metastatic potential. Histopathology 2019, 75, 213-224. [CrossRef]

179. Meric-Bernstam, F.; Shukla, N.; Peled, N.; Landman, Y.; Onitilo, A.; Montez, S.; Ku, N.C.; Hyman, D.M.; Drilon, A.; Hong, D.S Activity of larotrectinib, a highly selective inhibitor of tropomyosin receptor kinase, in TRK fusion breast cancers. Cancer Res. 2019, 79, P6-20-02. [CrossRef]

180. Goldenberg, D.M.; Stein, R.; Sharkey, R.M. The emergence of trophoblast cell-surface antigen 2 (TROP-2) as a novel cancer target. Oncotarget 2018, 9, 28989-29006. [CrossRef]

181. Ocean, A.J.; Starodub, A.N.; Bardia, A.; Vahdat, L.T.; Isakoff, S.J.; Guarino, M.; Messersmith, W.A.; Picozzi, V.J.; Mayer, I.A.; Wegener, W.A.; et al. Sacituzumab govitecan (IMMU-132), an anti-Trop-2-SN-38 antibody-drug conjugate for the treatment of diverse epithelial cancers: Safety and pharmacokinetics. Cancer 2017, 123, 3843-3854. [CrossRef]

182. Rugo, H.S.; Bardia, A.; Tolaney, S.M.; Arteaga, C.; Cortes, J.; Sohn, J.; Marmé, F.; Hong, Q.; Delaney, R.J.; Hafeez, A.; et al. TROPiCS-02: A Phase III study investigating sacituzumab govitecan in the treatment of HR+/HER2- metastatic breast cancer. Future Oncol. 2020, 16, 705-715. [CrossRef]

183. Bardia, A.; Mayer, I.A.; Diamond, J.R.; Moroose, R.L.; Isakoff, S.J.; Starodub, A.N.; Shah, N.C.; O'Shaughnessy, J.; Kalinsky, K.; Guarino, M.; et al. Efficacy and Safety of Anti-Trop-2 Antibody Drug Conjugate Sacituzumab Govitecan (IMMU-132) in Heavily Pretreated Patients with Metastatic Triple-Negative Breast Cancer. J. Clin. Oncol. 2017, 35, 2141-2148. [CrossRef]

184. Bardia, A.; Mayer, I.A.; Vahdat, L.T.; Tolaney, S.M.; Isakoff, S.J.; Diamond, J.R.; O'Shaughnessy, J.; Moroose, R.L.; Santin, A.D.; Abramson, V.G.; et al. Sacituzumab Govitecan-hziy in Refractory Metastatic Triple-Negative Breast Cancer. N. Engl. J. Med. 2019, 380, 741-751. [CrossRef] [PubMed]

185. Broner, E.C.; Alpert, G.; Gluschnaider, U.; Mondshine, A.; Solomon, O.; Sloma, I.; Rauch, R.; Izumchenko, E.; Aster, J.C.; Davis, M.; et al. AL101 mediated tumor inhibition in notch-altered TNBC PDX models. J. Clin. Oncol. 2019, 37, 1064. [CrossRef]

186. Locatelli, M.A.; Aftimos, P.; Dees, E.C.; LoRusso, P.M.; Pegram, M.D.; Awada, A.; Huang, B.; Cesari, R.; Jiang, Y.; Shaik, M.N.; et al. Phase I study of the gamma secretase inhibitor PF-03084014 in combination with docetaxel in patients with advanced triple-negative breast cancer. Oncotarget 2017, 8, 2320-2328. [CrossRef] [PubMed]

187. Gangrade, A.; Pathak, V.; Augelli-Szafran, C.E.; Wei, H.X.; Oliver, P.; Suto, M.; Buchsbaum, D.J. Preferential Inhibition of Wnt/ $\beta$-Catenin Signaling by Novel Benzimidazole Compounds in Triple-Negative Breast Cancer. Int. J. Mol. Sci. 2018, 19, 1524. [CrossRef] [PubMed]

188. Li, W.; Yang, H.; Li, X.; Han, L.; Xu, N.; Shi, A. Signaling pathway inhibitors target breast cancer stem cells in triple-negative breast cancer. Oncol Rep. 2019, 41, 437-446. [CrossRef] [PubMed]

189. Ahmed, K.; Koval, A.; Xu, J.; Bodmer, A.; Katanaev, V.L. Towards the first targeted therapy for triple-negative breast cancer: Repositioning of clofazimine as a chemotherapy-compatible selective Wnt pathway inhibitor. Cancer Lett. 2019, 449, 45-55. [CrossRef]

190. Xie, W.; Zhang, Y.; He, Y.; Zhang, K.; Wan, G.; Huang, Y.; Zhou, Z.; Huang, G.; Wang, J. A novel recombinant human Frizzled-7 protein exhibits antitumor activity against triple negative breast cancer via abating Wnt/ $\beta$-catenin pathway. Int. J. Biochem. Cell Biol. 2018, 103, 45-55. [CrossRef]

191. Bhateja, P.; Cherian, M.; Majumder, S.; Ramaswamy, B. The Hedgehog Signaling Pathway: A Viable Target in Breast Cancer? Cancers 2019, 11, 1126. [CrossRef]

192. Han, B.; Qu, Y.; Jin, Y.; Yu, Y.; Deng, N.; Wawrowsky, K.; Zhang, X.; Li, N.; Bose, S.; Wang, Q.; et al. FOXC1 Activates Smoothened-Independent Hedgehog Signaling in Basal-like Breast Cancer. Cell Rep. 2015, 13, 1046-1058. [CrossRef] 
193. Koike, Y.; Ohta, Y.; Saitoh, W.; Yamashita, T.; Kanomata, N.; Moriya, T.; Kurebayashi, J. Anti-cell growth and anticancer stem cell activities of the non-canonical hedgehog inhibitor GANT61 in triple-negative breast cancer cells. Breast Cancer 2017, 24, 683-693. [CrossRef]

194. Begalli, F.; Bennett, J.; Capece, D.; Verzella, D.; D’Andrea, D.; Tornatore, L.; Franzoso, G. Unlocking the NF-кB Conundrum: Embracing Complexity to Achieve Specificity. Biomedicines 2017, 5, 50. [CrossRef] [PubMed]

195. Messeha, S.S.; Zarmouh, N.O.; Mendonca, P.; Alwagdani, H.; Kolta, M.G.; Soliman, K.F.A. The inhibitory effects of plumbagin on the NF-қB pathway and CCL2 release in racially different triple-negative breast cancer cells. PLoS ONE 2018, 13, e0201116. [CrossRef] [PubMed]

196. Pan, H.; Zhou, W.; He, W.; Liu, X.; Ding, Q.; Ling, L.; Zha, X.; Wang, S. Genistein inhibits MDA-MB-231 triple-negative breast cancer cell growth by inhibiting NF-kB activity via the Notch-1 pathway. Int. J. Mol. Med. 2012, 30, 337-343. [CrossRef] [PubMed]

197. Labbozzetta, M.; Poma, P.; Vivona, N.; Gulino, A.; D'Alessandro, N.; Notarbartolo, M. Epigenetic changes and nuclear factor- $\kappa B$ activation, but not microRNA-224, downregulate Raf-1 kinase inhibitor protein in triple-negative breast cancer SUM 159 cells. Oncol. Lett. 2015, 10, 3807-3815. [CrossRef]

198. Dent, R.; Oliveira, M.; Isakoff, S.J.; Im, S.A.; Espié, M.; Blau, S.; Tan, A.R.; Saura, C.; Wongchenko, M.J.; Xu, N.; et al. Final results of the double-blind placebo-controlled randomized phase 2 LOTUS trial of first-line ipatasertib plus paclitaxel for inoperable locally advanced/metastatic triple-negative breast cancer. Breast Cancer Res. Treat. 2021, 189, 377-386.

199. Schmid, P.; Abraham, J.; Chan, S.; Wheatley, D.; Brunt, A.M.; Nemsadze, G.; Baird, R.D.; Park, Y.H.; Hall, P.S.; Perren, T.; et al. Capivasertib Plus Paclitaxel Versus Placebo Plus Paclitaxel ss First-Line Therapy for Metastatic Triple-Negative Breast Cancer: The PAKT Trial. J. Clin. Oncol. 2020, 38, 423-433. [CrossRef]

200. Qin, J.J.; Yan, L.; Zhang, J.; Zhang, W.D. STAT3 as a potential therapeutic target in triple negative breast cancer: A systematic review. J. Exp. Clin. Cancer Res. 2019, 38, 195. [CrossRef]

201. Koff, J.L.; Ramachandiran, S.; Bernal-Mizrachi, L. A time to kill: Targeting apoptosis in cancer. Int. J. Mol. Sci. 2015, 16, 2942-2955. [CrossRef]

202. Forero-Torres, A.; Varley, K.E.; Abramson, V.G.; Li, Y.; Vaklavas, C.; Lin, N.U.; Liu, M.C.; Rugo, H.S.; Nanda, R.; Storniolo, A.M.; et al. TBCRC 019: A Phase II Trial of Nanoparticle Albumin-Bound Paclitaxel with or without the Anti-Death Receptor 5 Monoclonal Antibody Tigatuzumab in Patients with Triple-Negative Breast Cancer. Clin. Cancer Res. 2015, 21, 2722-2729. [CrossRef]

203. Greer, Y.E.; Gilbert, S.F.; Gril, B.; Narwal, R.; Peacock Brooks, D.L.; Tice, D.A.; Steeg, P.S.; Lipkowitz, S. MEDI3039, a novel highly potent tumor necrosis factor (TNF)-related apoptosis-inducing ligand (TRAIL) receptor 2 agonist, causes regression of orthotopic tumors and inhibits outgrowth of metastatic triple-negative breast cancer. Breast Cancer Res. 2019, 21, 27. [CrossRef]

204. Wang, S.; Bai, L.; Lu, J.; Liu, L.; Yang, C.Y.; Sun, H. Targeting inhibitors of apoptosis proteins (IAPs) for new breast cancer therapeutics. J. Mammary Gland Biol. Neoplasia 2012, 17, 217-228. [CrossRef] [PubMed]

205. Bardia, A.; Parton, M.; Kümmel, S.; Estévez, L.G.; Huang, C.S.; Cortés, J.; Ruiz-Borrego, M.; Telli, M.L.; Martin-Martorell, P.; López, R.; et al. Paclitaxel with Inhibitor of Apoptosis Antagonist, LCL161, for Localized Triple-Negative Breast Cancer, Prospectively Stratified by Gene Signature in a Biomarker-Driven Neoadjuvant Trial. J. Clin. Oncol. 2018, 36, 3126-3133. [CrossRef]

206. Petrovic, N.; Ergun, S. miRNAs as Potential Treatment Targets and Treatment Options in Cancer. Mol. Diagn. Ther. 2018, 22, 157-168. [CrossRef] [PubMed]

207. Devulapally, R.; Sekar, N.M.; Sekar, T.V.; Foygel, K.; Massoud, T.F.; Willmann, J.K.; Paulmurugan, R. Polymer nanoparticles mediated codelivery of antimiR-10b and antimiR-21 for achieving triple negative breast cancer therapy. ACS Nano 2015, 9, 2290-2302. [CrossRef] [PubMed]

208. Hashemi, Z.S.; Moghadam, M.F.; Farokhimanesh, S.; Rajabibazl, M.; Sadroddiny, E. Inhibition of breast cancer metastasis by co-transfection of miR-31/193b-mimics. Iran. J. Basic Med. Sci. 2018, 21, 427-433. [PubMed]

209. Nakajima, H.; Ishikawa, Y.; Furuya, M.; Sano, T.; Ohno, Y.; Horiguchi, J.; Oyama, T. Protein expression, gene amplification, and mutational analysis of EGFR in triple-negative breast cancer. Breast Cancer 2014, 21, 66-74. [CrossRef]

210. Masuda, H.; Zhang, D.; Bartholomeusz, C.; Doihara, H.; Hortobagyi, G.N.; Ueno, N.T. Role of epidermal growth factor receptor in breast cancer. Breast Cancer Res. Treat. 2012, 136, 331-345. [CrossRef]

211. Baselga, J.; Gómez, P.; Greil, R.; Braga, S.; Climent, M.A.; Wardley, A.M.; Kaufman, B.; Stemmer, S.M.; Pêgo, A.; Chan, A.; et al Randomized phase II study of the anti-epidermal growth factor receptor monoclonal antibody cetuximab with cisplatin versus cisplatin alone in patients with metastatic triple-negative breast cancer. J. Clin. Oncol. 2013, 31, 2586-2592. [CrossRef]

212. Carey, L.A.; Rugo, H.S.; Marcom, P.K.; Mayer, E.L.; Esteva, F.J.; Ma, C.X.; Liu, M.C.; Storniolo, A.M.; Rimawi, M.F.; Forero-Torres, A.; et al. TBCRC 001: Randomized phase II study of cetuximab in combination with carboplatin in stage IV triple-negative breast cancer. J. Clin. Oncol. 2012, 30, 2615-2623. [CrossRef]

213. Matsuda, N.; Wang, X.; Lim, B.; Krishnamurthy, S.; Alvarez, R.H.; Willey, J.S.; Parker, C.A.; Song, J.; Shen, Y.; Hu, J.; et al. Safety and Efficacy of Panitumumab Plus Neoadjuvant Chemotherapy in Patients with Primary HER2-Negative Inflammatory Breast Cancer. JAMA Oncol. 2018, 4, 1207-1213. [CrossRef]

214. Cowherd, S.; Miller, L.D.; Melin, S.A.; Akman, S.; Isom, S.; Cole, J.; Pullikuth, A.; Lawrence, J.A. A phase II clinical trial of weekly paclitaxel and carboplatin in combination with panitumumab in metastatic triple negative breast cancer. Cancer Biol. Ther. 2015, 16, 678-683. [CrossRef] [PubMed] 
215. Chen, J.; Deng, S.; Zhang, Y.; Wang, C.; Hu, X.; Kong, D.; Liang, G.; Yuan, X.; Li, Y.; Wang, X. Apatinib enhances the antitumor effect of paclitaxel via the PI3K/p65/Bcl-xl pathway in triple-negative breast cancer. Ann. Transl. Med. 2021, 9, 1001. [CrossRef]

216. Gao, Z.; Shi, M.; Wang, Y.; Chen, J.; Ou, Y. Apatinib enhanced antitumor activity of cisplatin on triple-negative breast cancer through inhibition of VEGFR-2. Pathol. Res. Pract. 2019, 215, 152422. [CrossRef] [PubMed]

217. Li, Y.H.; Zhou, Y.; Wang, Y.W.; Tong, L.; Jiang, R.X.; Xiao, L.; Zhang, G.J.; Xing, S.S.; Qian, F.; Feng, J.Q.; et al. Comparison of apatinib and capecitabine (Xeloda) with capecitabine (Xeloda) in advanced triple-negative breast cancer as third-line therapy: A retrospective study. Medicine 2018, 97, e12222. [CrossRef] [PubMed]

218. El Guerrab, A.; Bamdad, M.; Kwiatkowski, F.; Bignon, Y.J.; Penault-Llorca, F.; Aubel, C. Anti-EGFR monoclonal antibodies and EGFR tyrosine kinase inhibitors as combination therapy for triple-negative breast cancer. Oncotarget 2016, 7, 73618-73637. [CrossRef] [PubMed]

219. Nabholtz, J.M.; Abrial, C.; Mouret-Reynier, M.A.; Dauplat, M.M.; Weber, B.; Gligorov, J.; Forest, A.M.; Tredan, O.; Vanlemmens, L.; Petit, T.; et al. Multicentric neoadjuvant phase II study of panitumumab combined with an anthracycline/taxane-based chemotherapy in operable triple-negative breast cancer: Identification of biologically defined signatures predicting treatment impact. Ann. Oncol. 2014, 25, 1570-1577. [CrossRef] [PubMed]

220. Giovannelli, P.; Di Donato, M.; Auricchio, F.; Castoria, G.; Migliaccio, A. Androgens Induce Invasiveness of Triple Negative Breast Cancer Cells Through AR/Src/PI3-K Complex Assembly. Sci. Rep. 2019, 9, 4490. [CrossRef] [PubMed]

221. Gucalp, A.; Tolaney, S.; Isakoff, S.J.; Ingle, J.N.; Liu, M.C.; Carey, L.A.; Blackwell, K.; Rugo, H.; Nabell, L.; Forero, A.; et al. Phase II trial of bicalutamide in patients with androgen receptor-positive, estrogen receptor-negative metastatic Breast Cancer. Clin. Cancer Res. 2013, 19, 5505-5512. [CrossRef]

222. Bonnefoi, H.; Grellety, T.; Tredan, O.; Saghatchian, M.; Dalenc, F.; Mailliez, A.; L'Haridon, T.; Cottu, P.; Abadie-Lacourtoisie, S.; You, B.; et al. A phase II trial of abiraterone acetate plus prednisone in patients with triple-negative androgen receptor positive locally advanced or metastatic breast cancer (UCBG 12-1). Ann. Oncol. 2016, 27, 812-818. [CrossRef]

223. Traina, T.A.; Miller, K.; Yardley, D.A.; Eakle, J.; Schwartzberg, L.S.; O’Shaughnessy, J.; Gradishar, W.; Schmid, P.; Winer, E.; Kelly, C.; et al. Enzalutamide for the Treatment of Androgen Receptor-Expressing Triple-Negative Breast Cancer. J. Clin. Oncol. 2018, 36, 884-890. [CrossRef]

224. Speers, C.; Zhao, S.G.; Chandler, B.; Liu, M.; Wilder-Romans, K.; Olsen, E.; Nyati, S.; Ritter, C.; Alluri, P.G.; Kothari, V.; et al. Androgen receptor as a mediator and biomarker of radioresistance in triple-negative breast cancer. NPJ Breast Cancer $2017,3,29$. [CrossRef] [PubMed]

225. Fallahpour, S.; Navaneelan, T.; De, P.; Borgo, A. Breast cancer survival by molecular subtype: A population-based analysis of cancer registry data. CMAJ Open 2017, 5, E734-E739. [CrossRef]

226. Malorni, L.; Shetty, P.B.; de Angelis, C.; Hilsenbeck, S.; Rimawi, M.F.; Elledge, R.; Osborne, C.K.; De Placido, S.; Arpino, G. Clinical and biologic features of triple-negative breast cancers in a large cohort of patients with long-term follow-up. Breast Cancer Res. Treat. 2012, 136, 795-804. [CrossRef] [PubMed]

227. Olivier, T.; Prasad, V. Sacituzumab govitecan in metastatic triple negative breast cancer (TNBC): Four design features in the ASCENT trial potentially favored the experimental arm. Transl Oncol. 2021, 15, 101248. [CrossRef] [PubMed]

228. Chen, J.; Han, M.; Liu, A.; Shi, B. Economic Evaluation of Sacituzumab Govitecan for the Treatment of Metastatic Triple-Negative Breast Cancer in China and the US. Front. Oncol. 2021, 11, 734594. [CrossRef] [PubMed]

229. Torres, E.T.R.; Emens, L.A. Emerging combination immunotherapy strategies for breast cancer: Dual immune checkpoint modulation, antibody-drug conjugates and bispecific antibodies. Breast Cancer Res. Treat. 2021, 191, 291-302. [CrossRef] [PubMed] 